\title{
Interannual Variation in Moisture Sources for the First Rainy Season in South China Estimated by the FLEXPART Model $\mathscr{a}$
}

\author{
Dongdong Peng, ${ }^{\mathrm{a}, \mathrm{b}}$ Tianjun Zhou, ${ }^{\mathrm{b}, \mathrm{c}}$ Yong Sun, ${ }^{\mathrm{b}}$ and Ailan Lin ${ }^{\mathrm{a}}$ \\ ${ }^{a}$ Institute of Tropical and Marine Meteorology, China Meteorological Administration, Guangzhou, China \\ ${ }^{\mathrm{b}}$ LASG, Institute of Atmospheric Physics, Chinese Academy of Sciences, Beijing, China \\ ${ }^{\mathrm{c}}$ University of Chinese Academy of Sciences, Beijing, China
}

(Manuscript received 13 April 2021, in final form 4 September 2021)

\begin{abstract}
The first rainy season (April-June) of South China includes the phases before and after the onset of the South China Sea summer monsoon (SCSSM). Abundant moisture supply is the key dynamic process for precipitation formation. Thus, we employ the FLEXPART model to explore the corresponding moisture sources for the two phases. Before the onset of SCSSM, land regions contribute more moisture to the precipitation over South China than the ocean sources. The main source regions are Southeast Asia (27.01\%), the South China Sea $(25.96 \%)$, South China (11.12\%), and the southern part of the northwestern Pacific $(10.23 \%)$. Land sources $(66.87 \%)$ play a more important role than ocean sources $(33.13 \%)$ in the interannual variations, with the contributions mainly from Southeast Asia (47.56\%) and the South China Sea (28.79\%). After the onset of SCSSM, the climatological contribution of ocean sources is larger than that of land regions, and the main source regions are the South China Sea (20.78\%), Southeast Asia (17.51\%), the Bay of Bengal $(13.76 \%)$, and South China (11.21\%). For the interannual variations, the contributions of land sources and ocean regions are comparable, and mainly from Southeast Asia (33.53\%) and the Bay of Bengal (32.26\%). The moisture transports for the interannual variations in first rainy season precipitation over South China before and after the onset of SCSSM are significantly correlated with the east-west contrast of sea surface temperature anomalies over northern part of North Pacific and the uniform warming over Indian Ocean, respectively. This study provides important guidance in improving the regional precipitation predictions and understanding the water resources changes.
\end{abstract}

KEYWORDS: Hydrologic cycle; Lagrangian circulation/transport; Precipitation; Interannual variability

\section{Introduction}

A key dynamic process in the formation of such precipitation events is the abundant moisture supply, which is contributed by the local evaporation and external moisture advection associated with the complex land-atmosphere-ocean processes and the interactions (Trenberth 1998; Pathak et al. 2014; Sun and Wang 2014; Li et al. 2016; Peng et al. 2020; Shi et al. 2020). Therefore, addressing the geographical moisture sources to understand the relative importance of different physical processes can provide important scientific guidance in improving the precipitation predictions as well as more confidence in facing the risk of climate change (Pathak et al. 2017; Zhong et al. 2018).

South China is a humid subtropical and tropical monsoon region characterized by abundant ecological resources and a dense population (Fig. 1a). More than $40 \%$ of the total annual precipitation occurring over South China is concentrated in

¿ Denotes content that is immediately available upon publication as open access.

Supplemental information related to this paper is available at the Journals Online website: https://doi.org/10.1175/JCLI-D-210289.s1.

Corresponding author: Dongdong Peng, pengdd.ac@hotmail. com
April-June, which is termed the first rainy season (FRS) for the local region (Gu et al. 2018; L. Huang et al. 2018). The FRS precipitation in South China is characterized by a high intensity, long duration, and wide range, resulting in a great influence on the local ecological environment and the development of society (Wu et al. 2011). Therefore, addressing the geographical moisture sources for FRS precipitation over South China is of great importance to both science and society.

As there is great difference in the atmospheric circulation before and after the onset of South China Sea summer monsoon (SCSSM), the moisture transport processes associated with climatological FRS precipitation in South China can be classified into two types, as illustrated in Fig. S1 in the online supplemental material (Gao et al. 2001; He et al. 2001; Chi et al. 2005; Chang et al. 2006; Yuan et al. 2010; Chen and Luo 2018; Shi et al. 2020). Before the onset of SCSSM, precipitation in South China is mainly induced by the weather front (the arbitrary front associated with a low pressure system), and the corresponding moisture is associated with the northwesterlies over the midlatitude regions of Eurasia, the westerlies to the south of the Tibetan Plateau, the easterly winds over the East China Sea and western Pacific Ocean, the southwesterlies over the Bay of Bengal, and the southeasterly winds over the South China Sea (Chi et al. 2005; Chang et al. 2006; Chen and Luo 2018). After the onset of SCSSM, however, the precipitation in South China mainly results from the moisture associated with the southwesterlies over the Arabian Sea, the central and western parts of the Indian Ocean, and 
(a)

\section{Subregion}

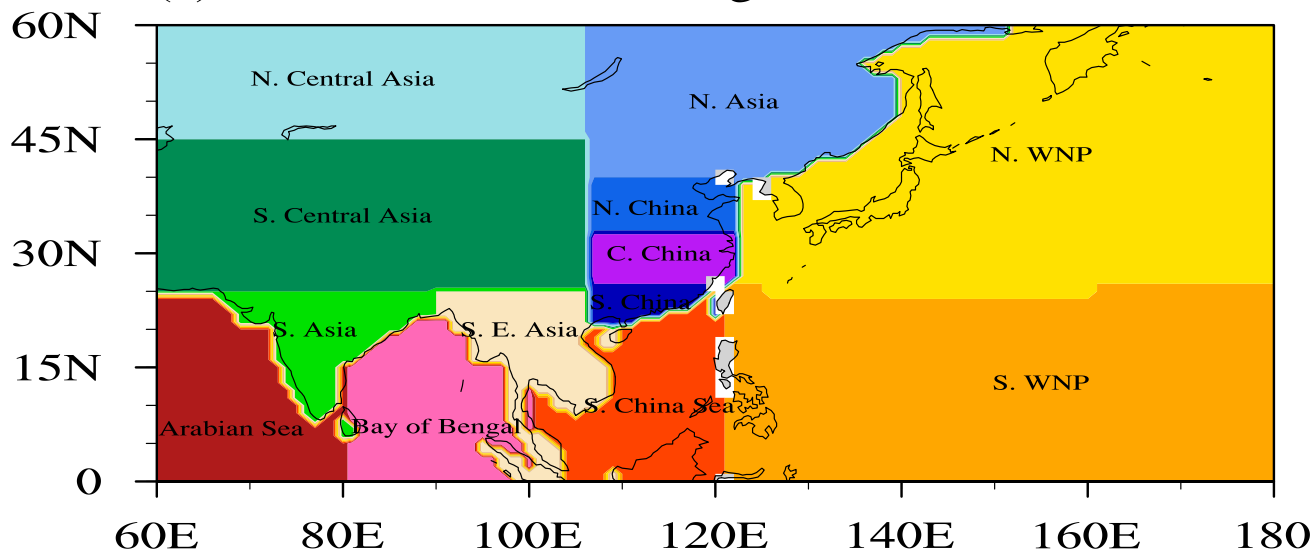

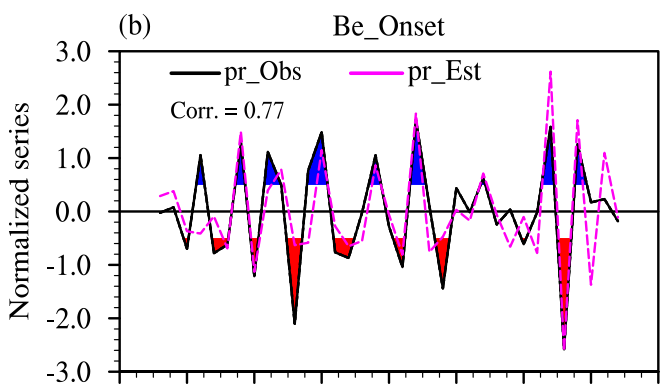

197819831988199319982003200820132018 (d)

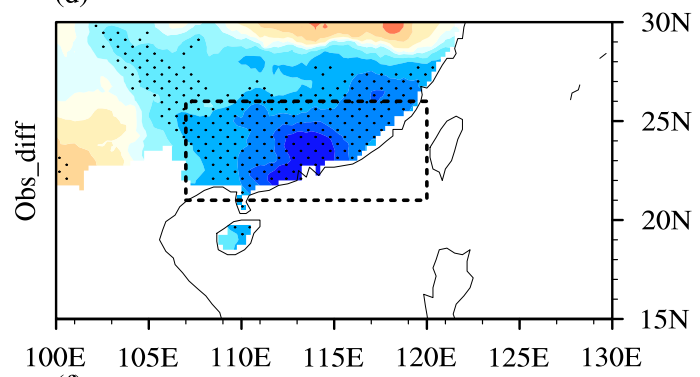

(f)
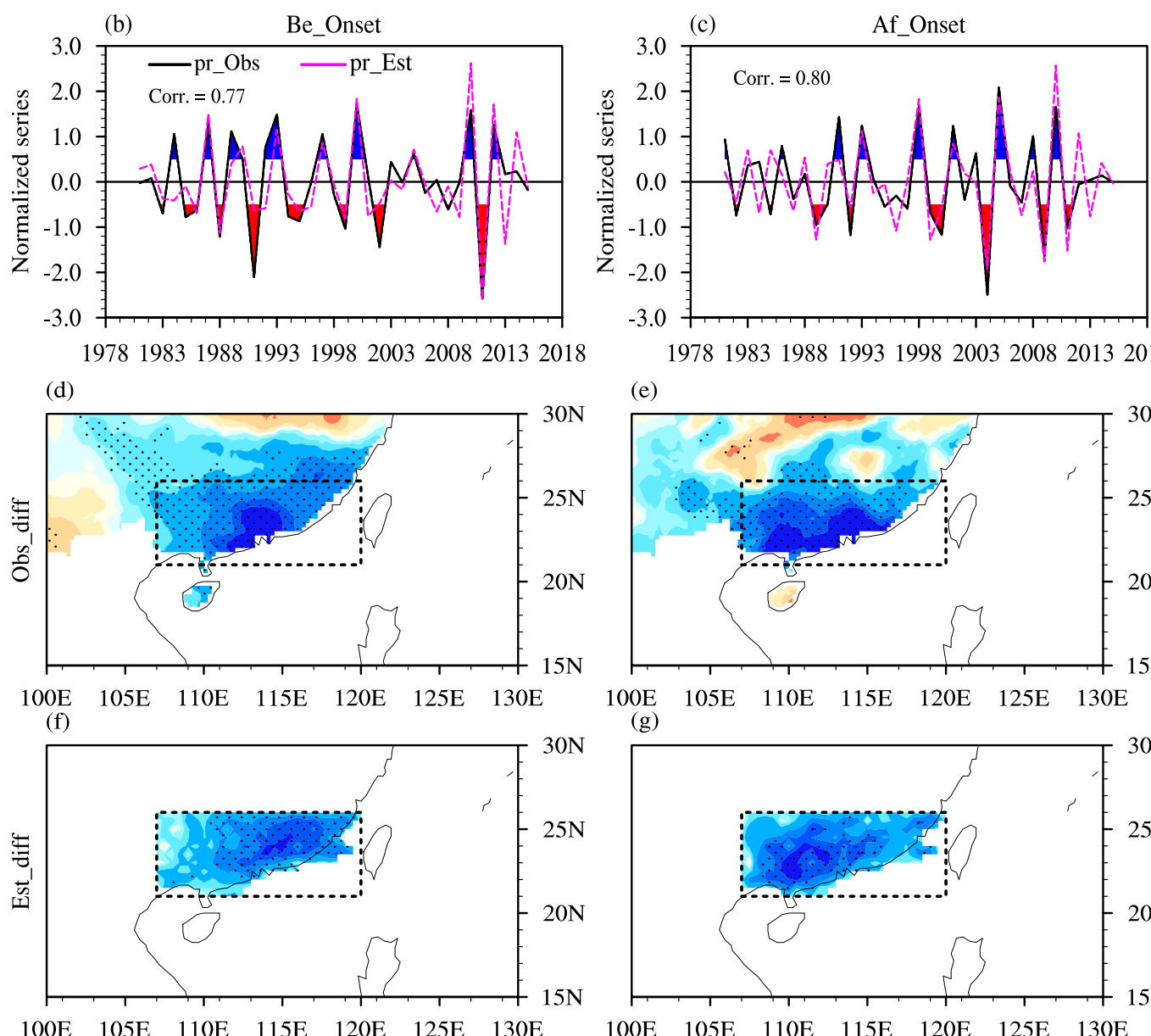

197819831988199319982003200820132018 (e)

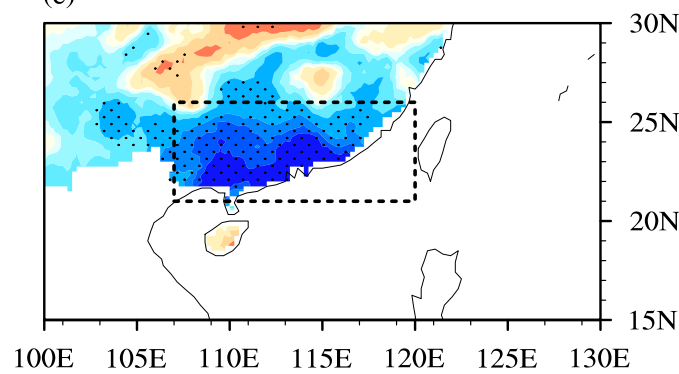

(g)

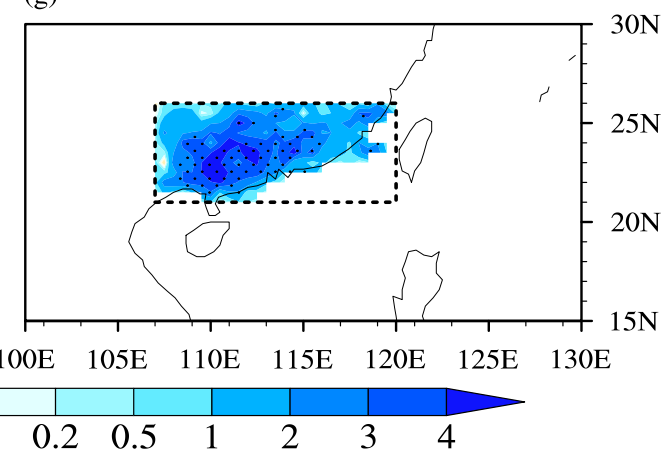

FIG. 1. Distributions of subregions, as well as the observed and FLEXPART model-estimated FRS precipitation in South China. (a) The distributions for the 13 major regions, namely, South China (S. China), Central China (C. China), North China (N. China), North Asia (N. Asia), North Central Asia (N. Central Asia), South Central Asia (S. Central Asia), South Asia (S. Asia), Southeast Asia (S. E. Asia), the northern part of the western North Pacific (N. WNP), the southern part of the western North Pacific (S. WNP), the South China Sea (S. China Sea), the Arabian Sea, and the Bay of Bengal. (b),(c) Normalized time series of 5-yr high-pass filtered regional averaged precipitation derived from observations (black lines) and model estimations (red lines) for the phases before and after the onset of 
the southeasterly winds over the South China Sea (Chi et al. 2005; Chang et al. 2006; Chen and Luo 2018).

The FRS precipitation over South China shows obvious interannual variation, which is correlated with changes in the western North Pacific subtropical high (WNPSH) and the subtropical westerly jet at a high troposphere level over East Asia (Liang and Wu 2001; Yang and Sun 2005; Yuan et al. 2010; Qiang and Yang 2013; Gu et al. 2018). Associated with the southward and westward displacement and the enhancement of the WNPSH, anomalous moisture convergence occurs over South China, thereby inducing more precipitation (Yang and Sun 2005; Qiang and Yang 2013; Gu et al. 2018). The southward displacement of the subtropical westerly jet over East Asia could result in anomalous divergence that could occur at a high level of the troposphere and thus enhance deep convection over South China, favoring more precipitation (Qiang and Yang 2013).

The interannual variation in FRS precipitation in South China is also associated with local meridional circulation changes. In association with the anomalous ascending branch of Hadley circulation over the western Pacific, the enhanced descending branch over subtropical East Asia restrains convective activities over South China, weakening moisture convergence and reducing precipitation over South China (Cai et al. 2002; Qiang and Yang 2013). In addition, changes in sea surface temperature over the tropical Pacific and Indian Ocean can impact the interannual variation in FRS precipitation over South China by inducing anomalous atmospheric circulations to modulate the corresponding moisture transport (Chen and Qian 2005; Yao et al. 2016; Gu et al. 2018; Yuan et al. 2019).

The above results are mainly derived from an Eulerianmethod-based moisture budget analysis, which treats precipitation as the sum of moisture convergence, changes in precipitable water, and local evaporation (Wang and Zhou 2005; Seager et al. 2010; Feng and Zhou 2012; Peng and Zhou 2017; Peng et al. 2018). This method can sufficiently describe the strength and pathway of moisture transport. Nonetheless, the interval processes of moisture in reaching target regions cannot be accurately identified based on this method, which introduces difficulty in accurately measuring the contribution of different moisture source regions (Sodemann et al. 2008; Sun and Wang 2014).

Unlike the Eulerian method focusing on the temporal variations in meteorological elements over a fixed region, the Lagrangian method describes the temporal variations in meteorological elements of the specific particle. The Lagrangian method can simulate the moisture diffusions forward in time or trace the source regions backward in time along the moving trajectories (Sun and Wang 2014; Huang and Cui 2015;
Jiang et al. 2017; Peng et al. 2020). As a result, the moisture uptake or release processes along the moving trajectories as well as the contribution of different moisture source regions can be accurately identified (Gimeno et al. 2010; Drumond et al. 2011; Salih et al. 2016; Bohlinger et al. 2017). Therefore, the Lagrangian method is advantageous in accurately detecting geographical moisture source regions and has been widely used in moisture source studies at both global and regional scales (Stohl and James 2004, 2005; Durán-Quesada et al. 2010; Sun and Wang 2014; Huang and Cui 2015; Jiang et al. 2017; Li et al. 2020; Peng et al. 2020).

The Lagrangian method has also been employed in many studies to reveal the moisture sources associated with precipitation over South China (Drumond et al. 2011; Sun and Wang 2015; Li et al. 2016; Chen and Luo 2018; W. Huang et al. 2018; Yang et al. 2018; Li et al. 2020). The moisture sources for the mean precipitation in South China vary greatly between different seasons, with the main contributors being the western Pacific Ocean during the cold season; however, the Indian and Pacific Oceans provide nearly equal contributions during the warm season (Drumond et al. 2011; Sun and Wang 2015). For persistent heavy rainfall occurring over South China, the corresponding moisture is mainly contributed by the South China Sea and the central part of the Indian Ocean, followed by the northwestern Pacific Ocean and eastern part of the Indian Ocean during the summer, but by the northwestern Pacific and North China, followed by central part of the Indian Ocean and the inland areas of Eurasia during winter (Li et al. 2016).

A recent study has focused on FRS precipitation over South China to address the corresponding moisture sources at the climatological mean time scale (Chen and Luo 2018). This study suggests that the South China Sea is the largest contributor to FRS precipitation occurring over South China for both the periods before and after the onset of SCSSM, but that the second contributor shifts from the Pacific Ocean to the Bay of Bengal as a result of monsoon onset (Chen and Luo 2018). However, those results mainly focus on the long-term climatological mean time scale. The interannual variations in the moisture sources associated with FRS precipitation over South China have not been addressed based on the Lagrangian method in previous studies. Thus, we employ the FLEXPART model and a moisture-source detection method considering the interval process to achieve this goal. In this study, we show evidence that land sources play a more important role than ocean sources in the interannual variations in moisture sources associated with FRS precipitation in South China before the onset of SCSSM but a nearly comparable role after the onset of SCSSM.

SCSSM, respectively. Blue and red shading indicates wet and dry years, respectively. (d),(e) Spatial patterns for the composite differences of observed precipitation in South China between wet and dry years before and after the onset of SCSSM, respectively. (f),(g) Results for the corresponding model estimations. Black dots indicate significance at the $5 \%$ level (likewise in the following figures). Units: $\mathrm{mm} \mathrm{day}^{-1}$. Black dashed boxes indicate the study region of South China $\left(21^{\circ}-26^{\circ} \mathrm{N}, 107^{\circ}-120^{\circ} \mathrm{E}\right)$. 
The remainder of the paper is organized as follows. The observations and reanalysis datasets used, as well as the employed moisture source detection method, are introduced in section 2. In section 3, we analyze the moisture source detection results derived from the Lagrangian model. Finally, the main results are summarized in section 4 .

\section{Data and methods}

\section{a. Data description}

The observational and reanalysis datasets used in this study include the following.

1) The observed gridded daily precipitation data with a horizontal resolution of $0.5^{\circ} \times 0.5^{\circ}$ over China (CN05.1) cover the period from 1961 to the present (Wu and Gao 2013). CN05.1 is derived from the data of more than 2000 stations distributed across China based on ANUSPLIN software and provided by the National Climate Center, China Meteorological Administration.

2) The 6-hourly Climate Forecast System Reanalysis (CFSR) collected by the National Centers for Environmental Prediction (NCEP) at a horizontal resolution of $0.5^{\circ} \times 0.5^{\circ}$ is utilized (Saha et al. 2010, 2014). Note that both CFSR version 1 and 2 datasets are used in this study, which cover the periods from 1979 to 2010 and from 2011 to the present, respectively. The variables used are the geopotential height, horizontal wind field, vertical wind field, pressure, relative humidity, temperature, dewpoint temperature, land cover, planetary boundary layer height, and water equivalent of the accumulated snow depth. The CFSR version 1 and version 2 datasets can be retrieved from https://rda.ucar.edu/datasets/ds093.0/ and https://rda.ucar. edu/datasets/ds094.0/, respectively.

3) Monthly NCEP-NCAR Reanalysis version 1 at a horizontal resolution of $2.5^{\circ} \times 2.5^{\circ}$ covers the period from 1949 to the present (Kalnay et al. 1996). This dataset can be retrieved from https://www.esrl.noaa.gov/psd/data/gridded/ data.ncep.reanalysis.html.

4) The observed monthly Hadley Centre Sea Ice and Sea Surface Temperature dataset (HadISST) version 1.1, at a horizontal resolution of $1^{\circ} \times 1^{\circ}$, covers the period from 1870 to the present (Rayner et al. 2003). This dataset can be downloaded from the website https://www.metoffice. gov.uk/hadobs/hadisst/.

5) The definition of onset date for SCSSM is derived from the operational standard of National Climate Center, China Meteorological Administration (CMA 2017). The observed yearly datasets for the onset date of SCSSM are shown in Table 1.

\section{b. Model simulation}

The Lagrangian model FLEXPART v9.2, which was developed by the Norwegian Institute for Air Research, is employed in this study to address the moisture sources associated with FRS precipitation over South China (Stohl et al. 2005). Note that FLEXPART is an independent model driven
TABLE 1. The onset date of SCSSM. Units: pentad.

\begin{tabular}{cccccccc}
\hline \hline Year & Onset & Year & Onset & Year & Onset & Year & Onset \\
\hline 1979 & 27 & 1989 & 32 & 1999 & 30 & 2009 & 30 \\
1980 & 28 & 1990 & 28 & 2000 & 27 & 2010 & 29 \\
1981 & 30 & 1991 & 32 & 2001 & 26 & 2011 & 26 \\
1982 & 31 & 1992 & 28 & 2002 & 27 & 2012 & 28 \\
1983 & 29 & 1993 & 30 & 2003 & 29 & 2013 & 27 \\
1984 & 28 & 1994 & 25 & 2004 & 28 & 2014 & 32 \\
1985 & 30 & 1995 & 27 & 2005 & 30 & 2015 & 29 \\
1986 & 27 & 1996 & 26 & 2006 & 28 & 2016 & 29 \\
1987 & 32 & 1997 & 28 & 2007 & 29 & 2017 & 28 \\
1988 & 29 & 1998 & 28 & 2008 & 25 & & \\
\hline
\end{tabular}

by the specific input datasets rather than a standard climate model with extra tracking capability. FLEXPART can compute the trajectories of so-called particles to describe the transports of these tracers in the atmosphere, which is originally used to detect the long-range and mesoscale dispersion of air pollution from the specific sources (Stohl et al. 2005). This model enables the simulation of air particles along their forward moving trajectories in time to address their diffusion processes or backward in time to date their origins, showing good performance in studies associated with atmospheric transport (Stohl and James 2004; Sodemann et al. 2008; Drumond et al. 2011; Läderach and Sodemann 2016). Based on the analysis of changes in specific humidity along the moving trajectories of air particles, the moisture source regions can be well quantified. Thus, this model has been widely used in previous studies to address the geographical moisture origins associated with precipitation at both global and regional scales (Stohl and James 2004; Nieto et al. 2006; Sodemann et al. 2008; Gimeno et al. 2010; Sun and Wang 2015; Läderach and Sodemann 2016; Vázquez et al. 2016; Bohlinger et al. 2017).

In this study, the FLEXPART simulation is conducted forward in time by employing the CFSR dataset over the period of 1979-2017. In total, one million particles are released over the global region to equally split the entire global atmosphere with the same air mass by using the "domain-fill" mode. The model outputs include air particle data, including latitude, longitude, height above ground level, and specific humidity, among others at the global scale. Both the run and outputs of the model simulation occur at 6-h time intervals. The technical details of setting options for the model simulations are provided in Peng et al. (2020).

\section{c. Moisture source detection method}

In terms of the Lagrangian method, the change in the specific humidity of an air particle during a given time interval can be regarded as the net effect of evaporation and precipitation, which can be expressed as

$$
e-p=m \frac{\Delta q}{\Delta t}
$$

where $e, p$, and $m$ represent the evaporation, precipitation, and air mass, respectively. Based on the analysis of changes in 
TABLE 2. The information for the observed and model estimated 5-yr high-pass filtered time series of the regional-averaged FRS precipitation over South China; Be_Onset and Af_Onset indicate the phase before and after the onset of SCSSM, respectively.

\begin{tabular}{lccc}
\hline \hline Time & Types & Climate mean $\left(\mathrm{mm} \mathrm{day}^{-1}\right)$ & ${\text { Standard deviation }\left(\mathrm{mm} \mathrm{day}^{-1}\right)}^{\text {Be_Onset }}$ \\
& Observation & 6.74 & 1.04 \\
\multirow{2}{*}{ Af_Onset } & Estimation & 7.71 & 0.77 \\
& Observation & 8.91 & 1.24 \\
& Estimation & 10.05 & 1.04 \\
\hline
\end{tabular}

specific humidity along the moving trajectories of target air particles, the moisture source $(e-p>0)$ and sink $(e-p<0)$ regions can be identified. In reaching the target region from moisture source regions, the target air particles may undergo several cycles of moisture uptake (evaporation-dominated) or release (precipitation-dominated). These factors could result in a decrease in the moisture contribution for a specific moisture source region. Therefore, a moisture source attribution method from Sodemann et al. (2008) is employed in this study to address the moisture origins for FRS precipitation in South China. This method can accurately quantify the contributions of different moisture origins by considering the interval processes of moisture uptake and release along the moving trajectories and thus has been widely used in previous studies ( $\mathrm{Li}$ et al. 2020; Peng et al. 2020).

\section{d. Data processing and analysis method}

The air particles that precipitate (i.e., the specific humidity decreases) at the starting time over South China are selected to be tracked backward. The CFSR dataset has a 6-h time interval in this study. Thus, for each targeted daily precipitation event, the corresponding trajectories are tracked backward at four time steps $(0000,0600,1200$, and 1800 UTC) on the day of the precipitation event. Thus, the backward-tracing time of each air particle is set as 10 days (i.e., the mean residual time of moisture in the atmosphere) (Trenberth 1998; Numaguti 1999).

As a result, the target particles are tracked backward from the starting time $(t=0)$ to 10 days prior $(t=-240 \mathrm{~h})$. In this study, days 1 and 2 are from $t=-6 \mathrm{~h}$ to $t=-24 \mathrm{~h}$ and from $t=-30 \mathrm{~h}$ to $t=-48 \mathrm{~h}$, respectively. As there are many target trajectories, the $k$-means cluster method is employed to show the general information of moisture pathways associated with FRS precipitation in South China (Arthur and Vassilvitskii 2007). Note that the target air particles are first merged and then subjected to cluster analysis.

The FRS precipitation over South China can be classified into two phases by the SCSSM activities, the phase before the onset of SCSSM and that after the onset of SCSSM. Thus, the moisture sources for the FRS precipitation are analyzed from two groups based on the onset date of SCSSM, as seen in Table 1 . This study aims to address the interannual variations of the FRS precipitation over South China. To remove the influence of decadal variability, the 5-yr high-pass Lanczos filtering method is employed for the precipitation, atmospheric circulations, and the moisture source detection results. The Student's $t$ test is used in this study.

\section{Results}

\section{a. Moisture transport associated with FRS precipitation in} South China

The normalized time series of 5-yr high-pass filtered areaaveraged FRS precipitation over South China is shown in Figs. $1 \mathrm{~b}$ and $1 \mathrm{c}$. The climatological mean values of observed areaaveraged precipitation over South China during the phase before and after the onset of SCSSM are 6.74 and $8.91 \mathrm{~mm} \mathrm{day}{ }^{-1}$, and the standard deviations are 1.04 and $1.24 \mathrm{~mm} \mathrm{day}^{-1}$, respectively, showing obvious interannual variations (Table 2). As in previous studies (Yoo 2006; Gu et al. 2018), the dry and wet years are defined as the years with precipitation less than -0.5 and greater than 0.5 standard deviations with respect to the climate mean value, as denoted by the red and blue shading in Figs. $1 \mathrm{~b}$ and 1c, respectively. The spatial distributions of composite precipitation differences between wet and dry years are shown in Figs. 1d and 1e. During both the phases before and after the onset of SCSSM, significant changes in the observed precipitation can be found over nearly the whole region of South China (Figs. 1d,e).

The FLEXPART model shows high performance in capturing the observed time evolutions of regional FRS precipitation averaged over South China, with a correlation coefficient of 0.77 before and 0.80 after the onset of SCSSM, passing the $5 \%$ significance level threshold (Figs. 1b,c). The FLEXPART model tends to overestimate the climate mean value but underestimate the standard deviation of the observed FRS precipitation in South China (Table 2). For both the phases before and after the onset of SCSSM, the spatial patterns of the observed composite mean FRS precipitation differences between wet and dry years are also well reproduced by the FLEXPART model despite some discrepancies (Figs. 1f,g).

The spatial patterns of atmospheric circulations associated with the FRS precipitation over South China are shown in Fig. 2. As to the climate mean state before the onset of SCSSM, South China is dominated by the southwesterlies/ southerlies associated with the WNPSH extending from the lower $(850 \mathrm{hPa}$; Fig. $2 \mathrm{a})$ to the middle $(500 \mathrm{hPa}$; Fig. $2 \mathrm{c})$ level of the troposphere, which can transport the moisture from the South China Sea, northwestern Pacific Ocean, and Southeast Asia to the target region. After the onset of SCSSM, favored by both the deep low trough over the Bay of Bengal and the eastward and northward displacement of WNPSH (with respect to the results before the onset of SCSSM), South China is also dominated by southwesterlies and southerlies, which can transport the moisture from the South China Sea, 


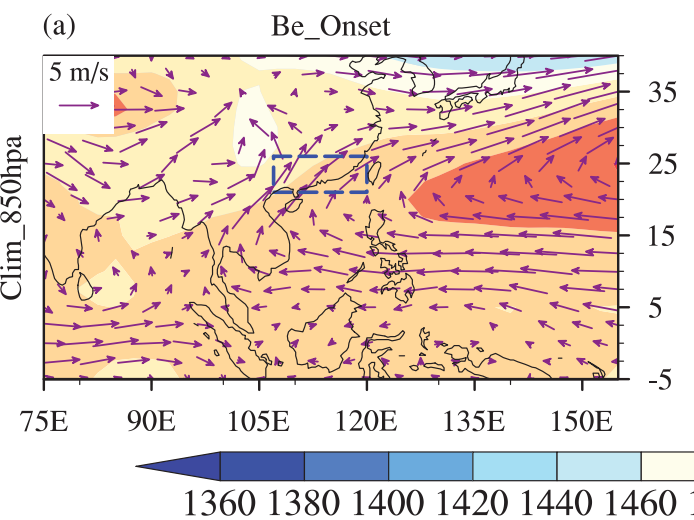

(c)

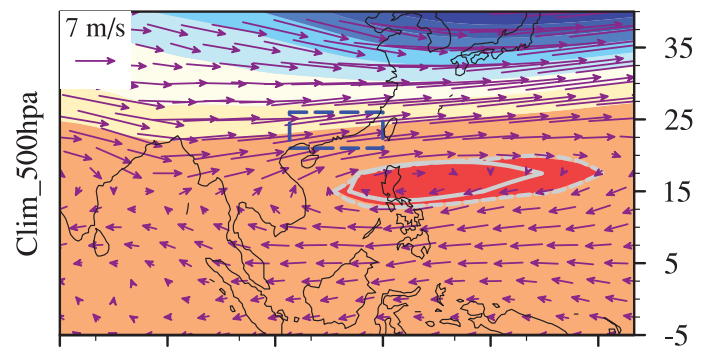

$75 \mathrm{E} \quad 90 \mathrm{E} \quad 105 \mathrm{E} \quad 120 \mathrm{E} \quad 135 \mathrm{E} \quad 150 \mathrm{E}$ (b)

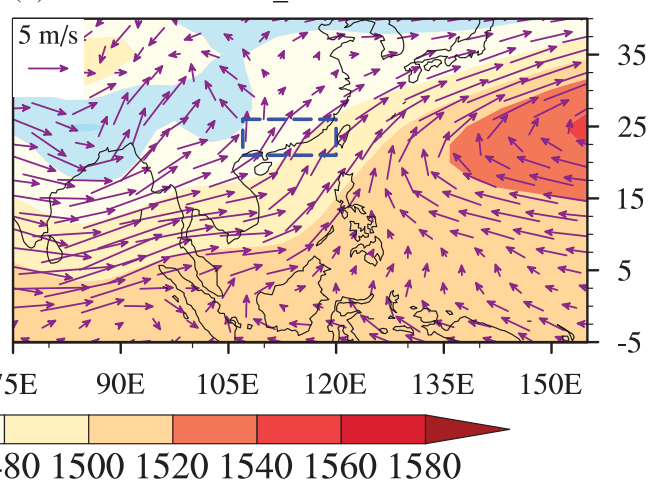

(d)

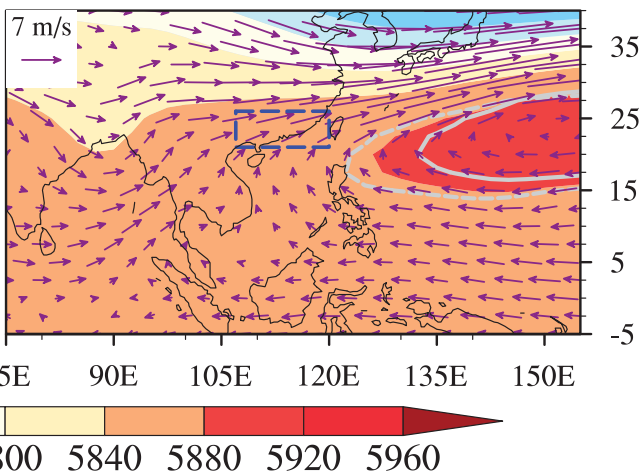

(f)

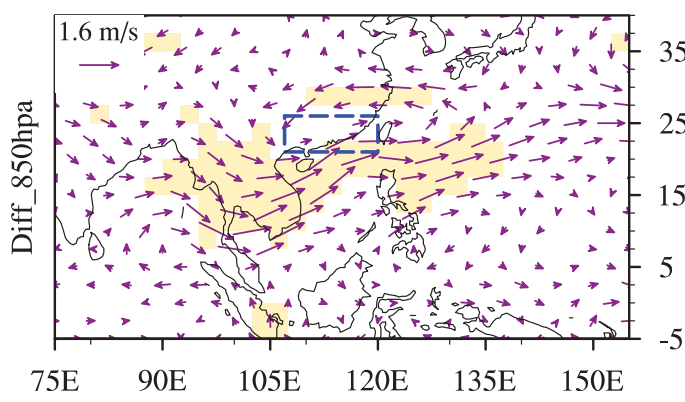

(g)

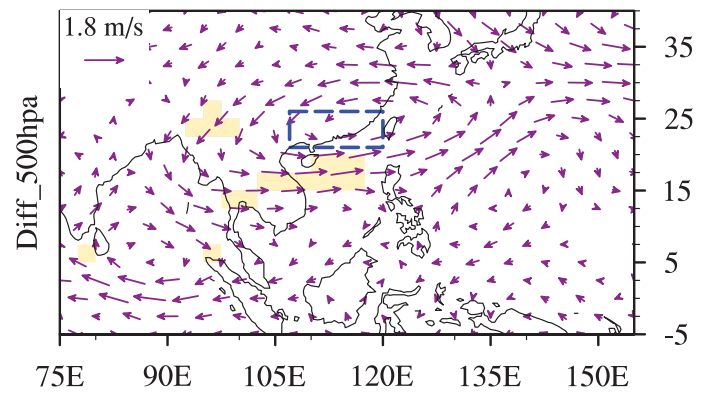

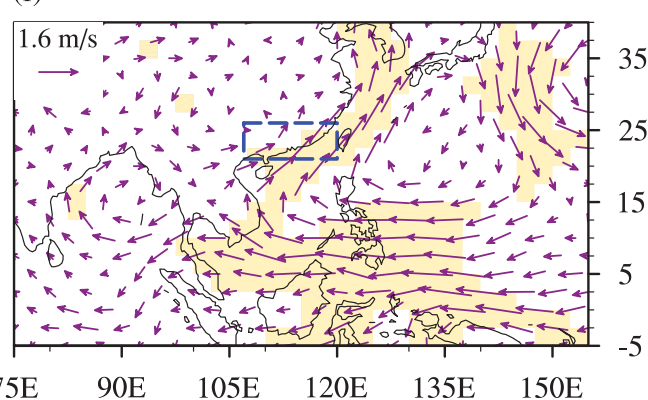

(h)

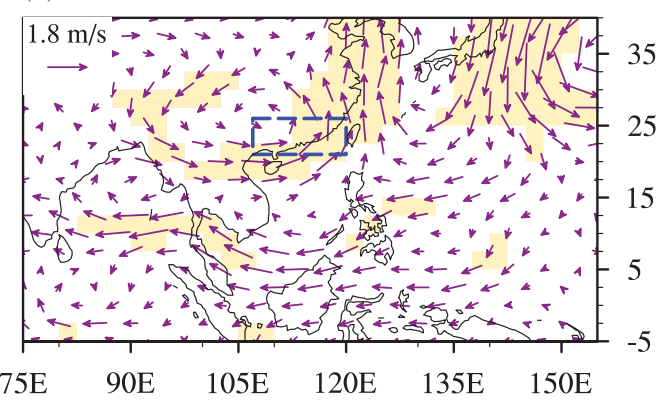

FIG. 2. Spatial patterns for the FRS horizontal winds and geopotential heights. Columns indicate the results (left) before and (right) after the onset of SCSSM, respectively. (a),(b) and (c),(d) Results for the climatological mean during 1979-2017 at 850 and $500 \mathrm{hPa}$, respectively. (e),(f) and (g),(h) Results for the composite differences between wet and dry years at 850 and $500 \mathrm{hPa}$, respectively. Solid and dashed gray lines in (c) and (d) indicate 5880 geopotential meters during dry and wet years, respectively. Vectors indicate horizontal winds ( $\left.\mathrm{m} \mathrm{s}^{-1}\right)$. Shadings in (a)-(d) indicate the geopotential height $(\mathrm{m})$. In (e)-(h), shading indicates the changes in the horizontal (meridional or zonal) winds at the $5 \%$ significance level. 
(a) AGL_traj

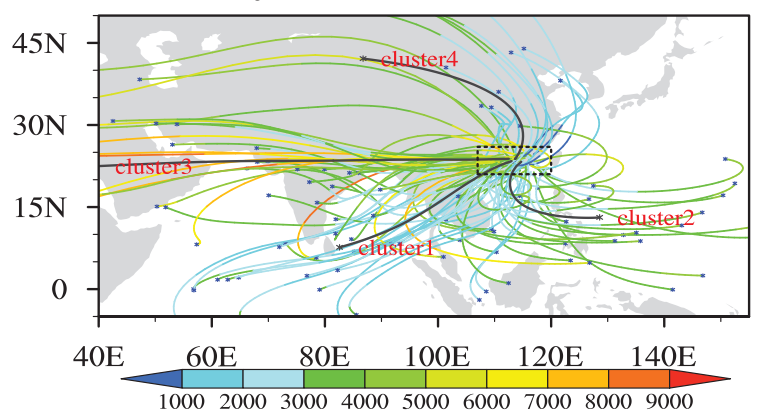

(b) q_traj

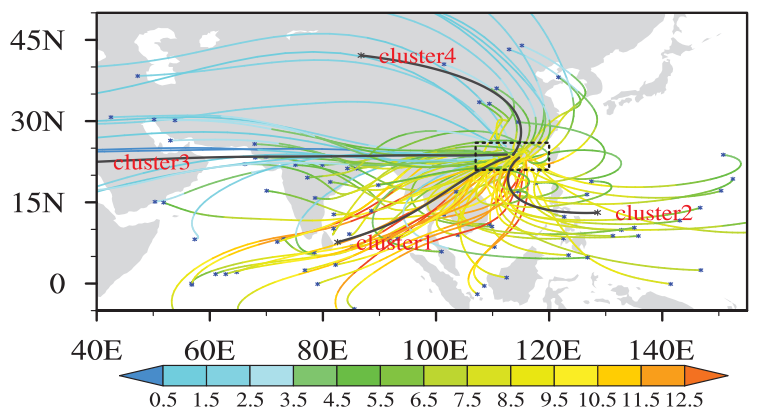

(c) AGL
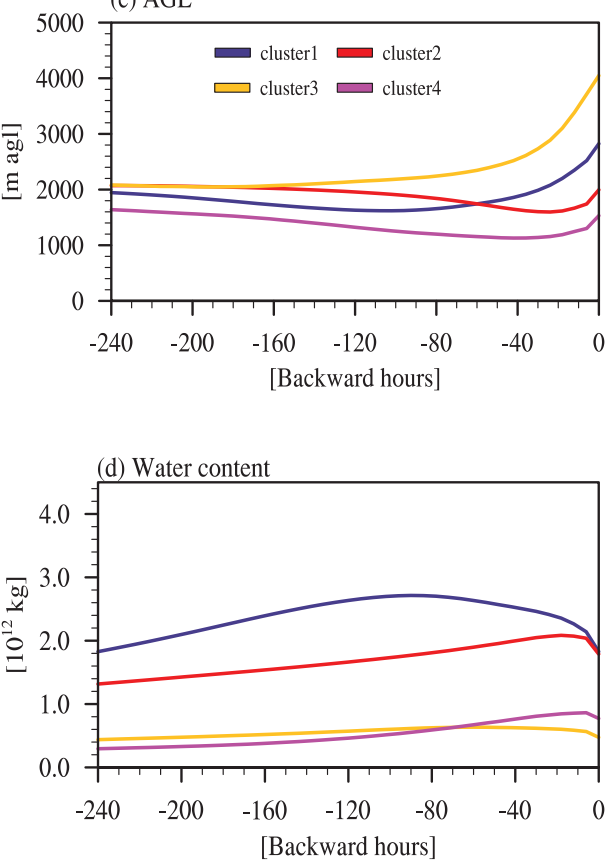

FIG. 3. The moving trajectories and corresponding changes in the specific humidity of air particles reaching South China in the FRS during 1979-2017. (a),(b) Changes in height [in meters above ground level (m AGL)] and specific humidity $\left(\mathrm{g} \mathrm{kg}^{-1}\right)$ along the moving trajectories derived from the cluster mean, respectively. The number of clusters is 100 for the color but 4 for the black trajectories. (c) The changes in the mean height for each cluster from the starting point 10 days ago in reaching South China. Units: $\mathrm{m} \mathrm{AGL}$. (d) As in (c), but for the changes in total water content (the product of air mass and specific humidity) for each cluster. Units: $10^{12} \mathrm{~kg}$. The blue, red, yellow, and magenta lines indicate the results for clusters $1,2,3$, and 4, respectively.

Southeast Asia, the northwestern Pacific Ocean, and the Bay of Bengal to the target region (Figs. 2b,d). At the middle level of the troposphere, the westerlies over subtropical East Asia can also transport moisture from midlatitude regions eastward into South China.

Compared to the results produced in dry years, an anomalous cyclone occurs over South China and expands from the lower to middle level of the troposphere during wet years before the onset of SCSSM (Figs. 2e,g). Thus, the southwesterlies of this cyclone can transport more moisture from regions to the southwest of South China into the target region. As to the results after the onset of SCSSM during wet years, South China is dominated by the anomalous southwesterlies associated with the anomalous anticyclone over northwestern Pacific Ocean at lower levels and the anomalous southerlies associated with anomalous cyclone over South China at middle levels of the troposphere (Figs. 2f,h). Besides, an anomalous anticyclone can be seen over South China Sea and Bay of Bengal. As a result, more moisture from the northwestern Pacific Ocean, the South China Sea, and the Bay of Bengal can be potentially transported into South China during wet years. For both the phases before and after the onset of SCSSM, the composite differences are consistent with the movement of the WNPSH. Compared to the climatological mean state, the WNPSH weakens and retreats eastward during dry years, whereas it is enhanced (with a much larger area than the climate mean) and moves westward during wet years (Figs. 2c,d). Note that the differences between the two phases are associated with the locations of the WNPSH, which moves northward and eastward after the onset of SCSSM.

The moving trajectories of target air particles derived from the FLEXPART model for the precipitation over South China during the whole FRS are classified into four clusters (Figs. 3a,b). In terms of the trajectory percentage, the air particles are mainly transported into South China northeastward from the Indian Ocean (cluster 1, with a value of $38.59 \%$ ), followed by transport northwestward from the northwestern Pacific Ocean (cluster 2, 29.98\%), eastward from the Indian subcontinent (cluster 3, 18.41\%), and southeastward from midlatitude regions over Eurasia (cluster 4, 13.03\%). These are evidenced by the probability distributions of particles associated with each cluster (Fig. S2). Note that the probability distributions are conducted referring to Suh et al. (2015).

For all four moisture channels, air particles tend to uptake moisture at the lower level of the troposphere before reaching South China and release moisture associated with an obvious lifting motion at the time air particles precipitate over South 
(a) Be_Onset

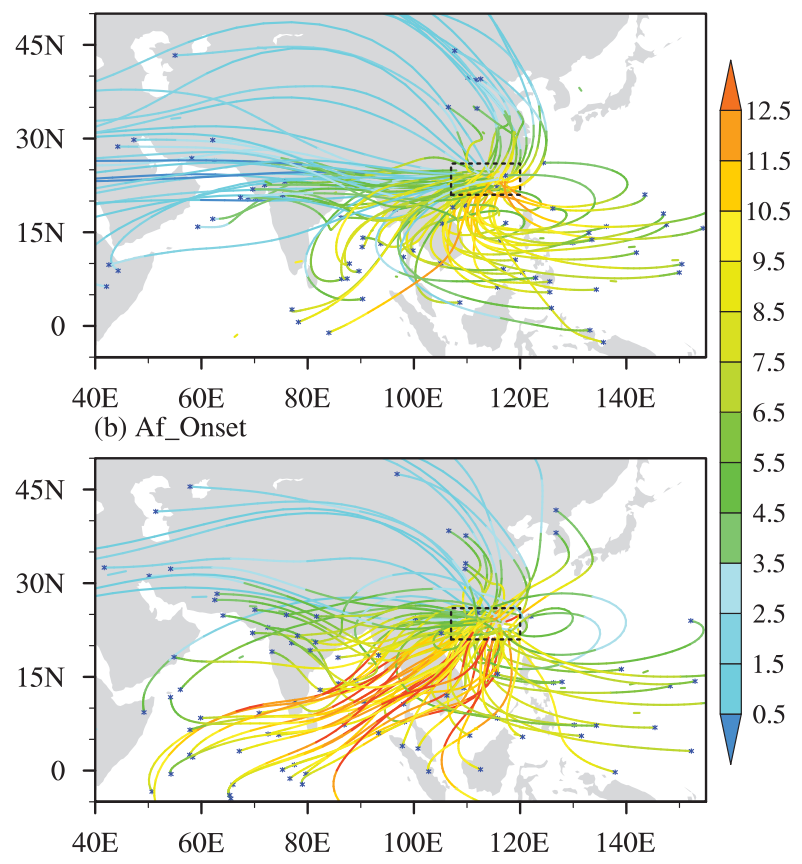

(c) Trajectory percentage

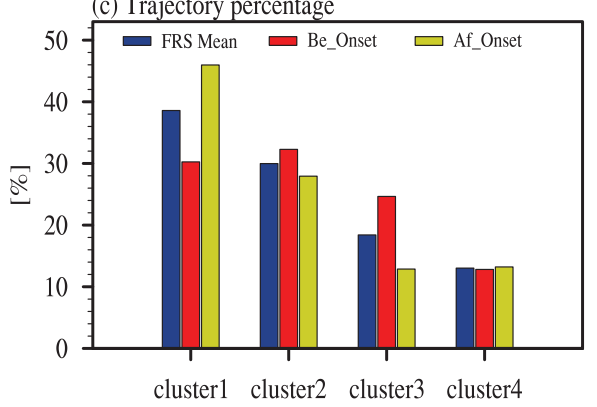

(d) Water content

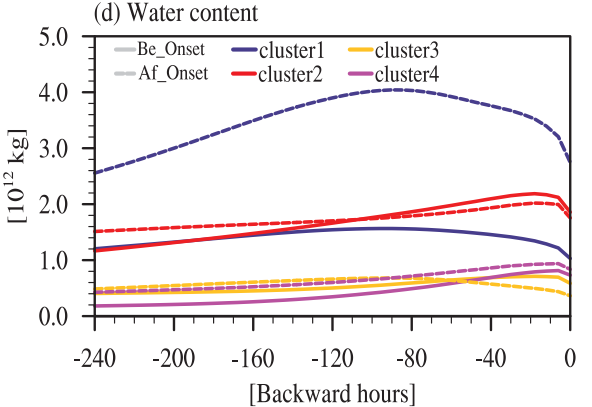

FIG. 4. The changes in the specific humidity along the moving air particle trajectories reaching South China in the FRS before and after the onset of SCSSM: (a) Be_Onset and (b) Af_Onset (unit: $\mathrm{g} \mathrm{kg}^{-1}$ ). (c) The ratios of trajectory number for each cluster (the four black clusters) to the total trajectories derived from the FRS mean (blue bars), before (red bars), and after (yellow bars) the onset of SCSSM (unit: \%). (d) The changes in the total water content of trajectories for each cluster in reaching South China from 10 days ago (unit: $10^{12} \mathrm{~kg}$ ). Solid and dashed lines indicate the results before and after the onset of SCSSM, respectively. The blue, red, yellow, and magenta lines indicate the results for clusters $1,2,3$, and 4 , respectively.

China (Figs. 3c,d). For clusters $2-4$, the moisture of air particles tends to increase along the whole moving trajectory before precipitating over South China. However, the moisture of target air particles in cluster 1 increases over hours -240 to -80 and then decreases before reaching South China.

The changes in specific humidity along the moving trajectories of air particles in reaching South China during the two phases are shown in Fig. 4. The distributions of trajectories before (Fig. 4a) and after (Fig. 4b) the onset of SCSSM are similar to the FRS mean results (Fig. 3a). These results demonstrate that those four moisture clusters occur during both phases. The ratios of trajectories for cluster 1 , cluster 2 , cluster 3 , and cluster 4 are approximately $30.25 \%, 32.28 \%, 24.65 \%$, and $12.81 \%$ before the onset of SCSSM and $45.97 \%, 27.94 \%$, $12.87 \%$, and $13.22 \%$ after the onset of SCSSM, respectively (Fig. 4c). These can be clearly seen in the probability distributions of particles associated with each cluster for the two phases (Figs. S3 and S4).

The water content of cluster 2 is the largest during the phase before the onset of SCSSM (Fig. 4d). After the onset of SCSSM, however, the largest water content is seen in cluster 1. These demonstrate that moisture from Indian Ocean could play a more important role in the FRS precipitation after the onset of SCSSM than that before the onset of SCSSM. The changes in specific humidity along the moving trajectories for all four moisture pathways during the two phases are similar, with continuing moisture enhancement processes for clusters 2,3 , and 4 throughout all 10 days, but moisture releasing processes for cluster 1 occurred during the nearest 4 days before precipitation in South China. With respect to the results before the onset of SCSSM, the larger water content of cluster 1 is contributed by both the larger ratios of trajectories and the higher specific humidity, while the larger content of cluster 4 is mainly related with the relatively larger ratios of trajectories (Figs. 4a,b,d) after the onset of SCSSM.

The main moisture pathway of climatological precipitation over South China is the cluster 2 (by way of northwestern Pacific and South China Sea) before but cluster 1 (by way of Indian Ocean) after the onset of SCSSM, in line with the changes in atmospheric circulations associated with SCSSM activities. As to the interannual variations, South China is dominated by the southwesterlies for both the phases before and after the onset of SSSM but characterized by anomalous systems with different locations and intensities during wet years.

\section{b. Spatial patterns for the moisture changes of all target air particles}

Addressing the evolutions of spatial patterns for the changes in moisture content is a key step in revealing the ongoing moisture uptake/release processes along the moving 
Clim

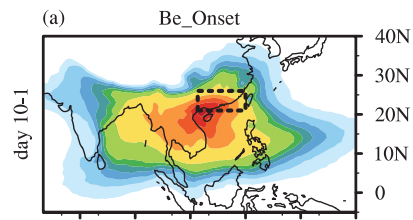

$75 \mathrm{E} \quad 90 \mathrm{E} \quad 105 \mathrm{E} \quad 120 \mathrm{E} \quad 135 \mathrm{E} \quad 150 \mathrm{E}$

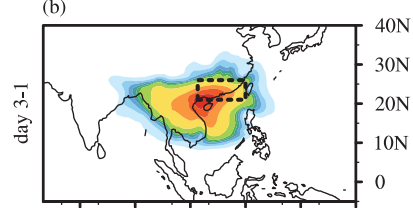

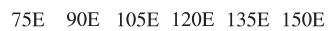

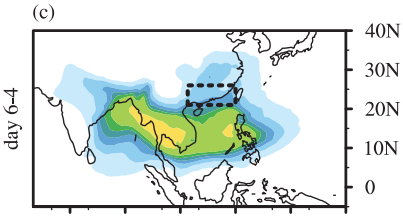

$75 \mathrm{E} \quad 90 \mathrm{E} \quad 105 \mathrm{E} \quad 120 \mathrm{E} \quad 135 \mathrm{E} \quad 150 \mathrm{E}$

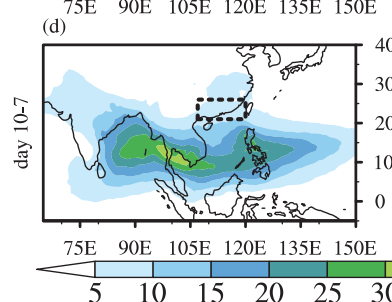

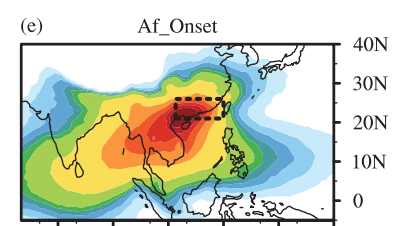

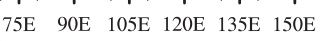
(f)

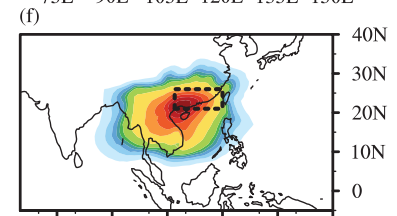

$75 \mathrm{E} \quad 90 \mathrm{E} \quad 105 \mathrm{E} \quad 120 \mathrm{E} \quad 135 \mathrm{E} \quad 150 \mathrm{E}$ (g)

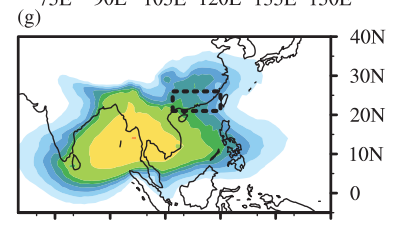

$75 \mathrm{E} \quad 90 \mathrm{E} \quad 105 \mathrm{E} \quad 120 \mathrm{E} \quad 135 \mathrm{E} \quad 150 \mathrm{E}$ (h)

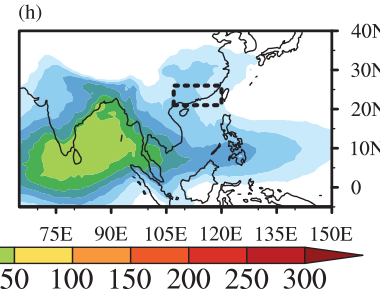

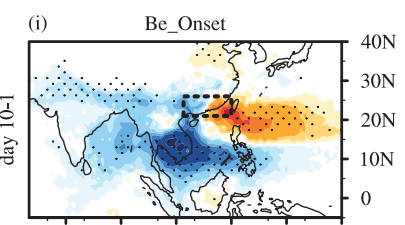

$75 \mathrm{E} \quad 90 \mathrm{E} \quad 105 \mathrm{E} \quad 120 \mathrm{E} \quad 135 \mathrm{E} \quad 150 \mathrm{E}$ (j)

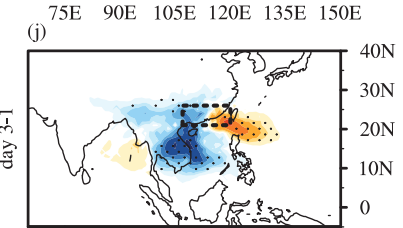

$75 \mathrm{E} \quad 90 \mathrm{E} \quad 105 \mathrm{E} \quad 120 \mathrm{E} \quad 135 \mathrm{E} \quad 150 \mathrm{E}$ (k)

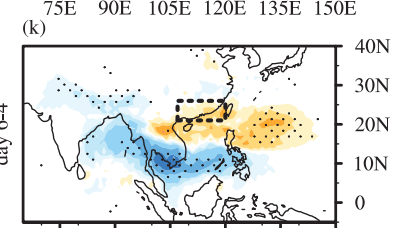

$\begin{array}{llllll}75 \mathrm{E} & 90 \mathrm{E} \quad 105 \mathrm{E} & 120 \mathrm{E} & 135 \mathrm{E} & 150 \mathrm{E}\end{array}$
(1)
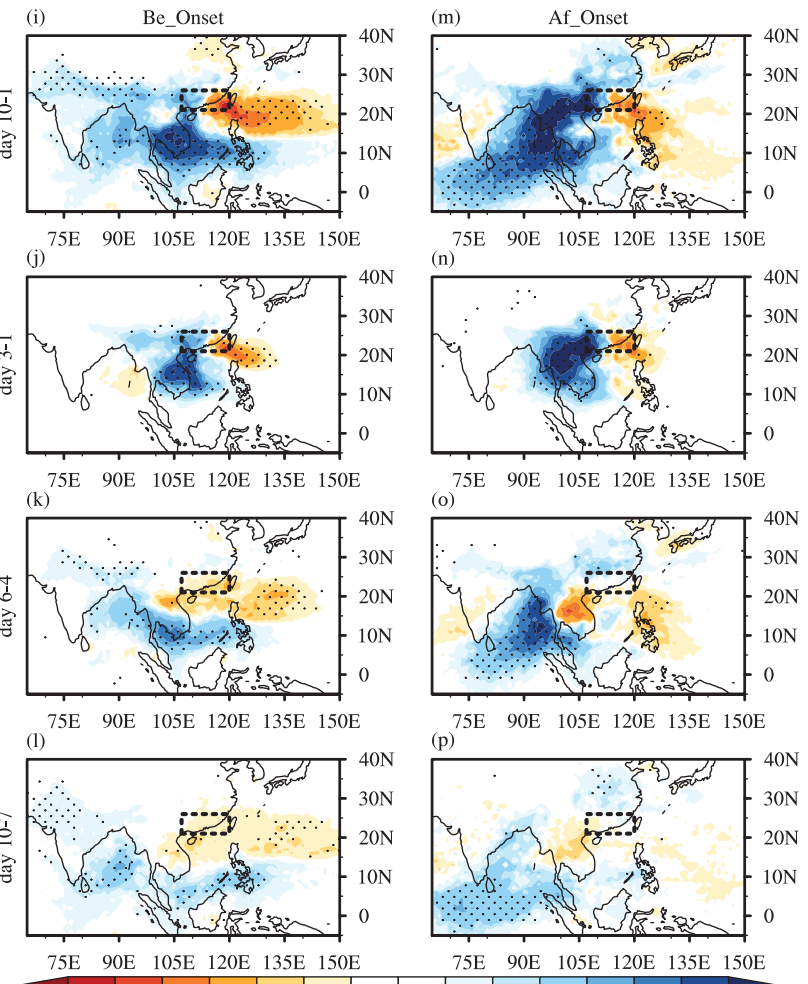

$\begin{array}{llllllll}75 \mathrm{E} & 90 \mathrm{E} & 105 \mathrm{E} & 120 \mathrm{E} & 135 \mathrm{E} & 150 \mathrm{E}\end{array}$ (n)

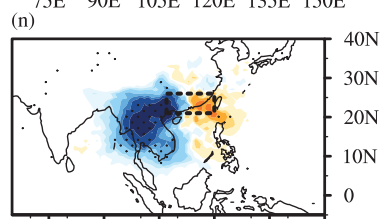

$75 \mathrm{E} \quad 90 \mathrm{E} \quad 105 \mathrm{E} \quad 120 \mathrm{E} \quad 135 \mathrm{E} \quad 150 \mathrm{E}$ (o)

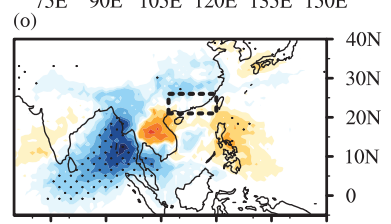

$75 \mathrm{E} \quad 90 \mathrm{E} \quad 105 \mathrm{E} \quad 120 \mathrm{E} \quad 135 \mathrm{E} \quad 150 \mathrm{E}$ (p)

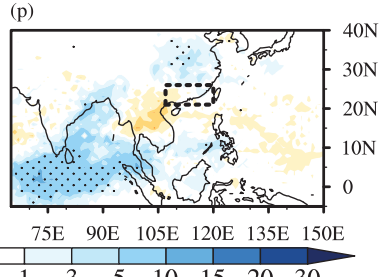

FIG. 5. Spatial patterns of the water contents derived from all the target back-tracking trajectories. (first column), (second column) Climatological mean results for FRS precipitation during 1979-2017 before and after the onset of SCSSM, respectively. (third column),(fourth column) Results for the composite differences between wet and dry years before and after the onset of SCSSM, respectively. The rows indicate (from top to bottom) the results over back-tracking days 10-1, 3-1, 6-4, and 10-7, respectively. Units: $\mathrm{kg} \mathrm{m}^{-2}$.

trajectories. Thus, the spatial distributions of moisture changes for all the target air particles are illustrated in this section.

Figure 5 shows the spatial patterns of the mean water contents associated with all the target air particles. As to the climate state before the onset of SCSSM, a large high water content band (larger than $150 \mathrm{~kg} \mathrm{~m}^{-2}$ ) expands eastward and northeastward from the eastern part of Southeast Asia to the South China Sea and into South China over the whole 10-day back-tracking period, respectively (Fig. 5a). The result that the highest center of water content is away from South China implies that the local evaporation may not be the main contributor to the precipitation over South China. The spatial distributions of water content over days $3-1$ are similar to the distributions of the large band over days 1-10, demonstrating that the moisture from South China, Southeast Asia, and the northern part of the South China Sea over the last 3 days may play an important role in the precipitation occurring over South China. The water content over the Bay of Bengal mainly originates from days $4-6$, followed by days $7-10$. For the northwestern Pacific, the water content mainly originates from days $7-10$, followed by days $4-6$. The distributions of mean water content after the onset of SCSSM are similar to the results before the onset of SCSSM despite the larger magnitudes (the second column of Fig. 5).

Compared to the results obtained during dry years during the phase before the onset of SCSSM, the water content over southern part of Southeast Asia and the South China Sea, the northern part of the Bay of Bengal, and the regions to the north of the Indian subcontinent increases significantly, while the water content over the regions to the east of South China decreases significantly over days 1-10 during wet years (Fig. 5i). The decrement in water content mainly occurs over days $1-3$, followed by days 4-6 and days $7-10$ (Figs. $5 j-1$ ). The increment in water content over the northern part of the Bay of Bengal and the regions to the north of the Indian subcontinent mainly occurs over days $4-6$, followed by days $7-10$. For the southern part of Southeast Asia and the South China Sea, water content enhancement mainly occurs over days $1-3$, followed by days 4-6.

For the phase after the onset of SCSSM, the water content increases significantly over most regions of Southeast Asia and the Bay of Bengal but decreases significantly over small portions to the southeast of South China over days 1-10 (Fig. $5 \mathrm{~m})$. The increment for Southeast Asia mainly occurs over days $1-3$, while for Bay of Bengal it mainly occurs over days 


\section{Clim}

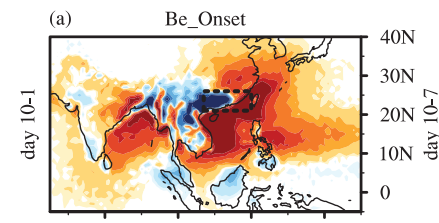

$\begin{array}{llll}80 \mathrm{E} & 100 \mathrm{E} \quad 120 \mathrm{E} \quad 140 \mathrm{E}\end{array}$

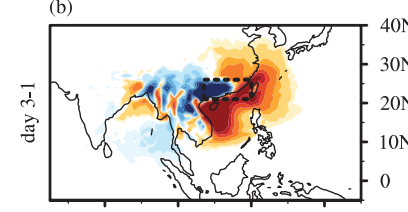

$80 \mathrm{E} \quad 100 \mathrm{E} \quad 120 \mathrm{E} \quad 140 \mathrm{E}$

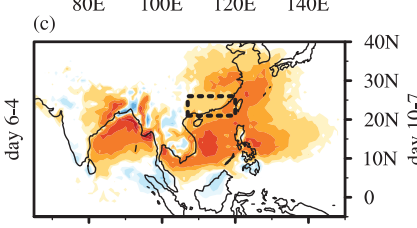

$80 \mathrm{E} \quad 100 \mathrm{E} \quad 120 \mathrm{E} \quad 140 \mathrm{E}$

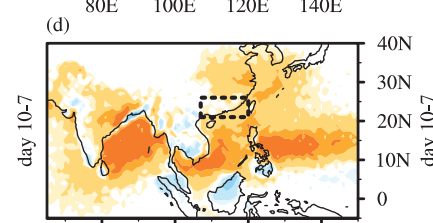

$80 \mathrm{E} \quad 100 \mathrm{E} \quad 120 \mathrm{E} \quad 140 \mathrm{E}$

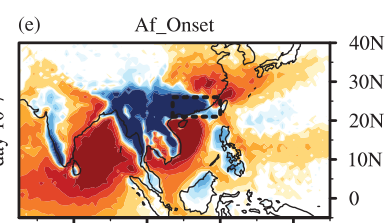

$80 \mathrm{E} \quad 100 \mathrm{E} \quad 120 \mathrm{E} \quad 140 \mathrm{E}$

(f)

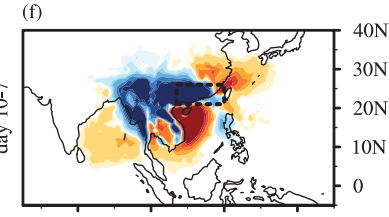

$80 \mathrm{E} \quad 100 \mathrm{E} \quad 120 \mathrm{E} \quad 140 \mathrm{E}$ (g)

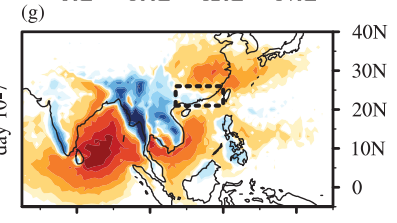

$80 \mathrm{E} \quad 100 \mathrm{E} \quad 120 \mathrm{E} \quad 140 \mathrm{E}$

(h)

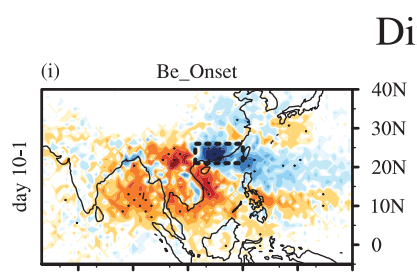

$\begin{array}{lllllllllllllllllll}75 \mathrm{E} & 90 \mathrm{E} & 105 \mathrm{E} & 120 \mathrm{E} & 135 \mathrm{E} & 150 \mathrm{E}\end{array}$ (j)

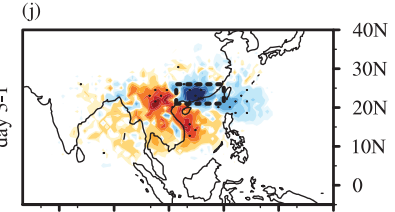

$\begin{array}{llllll}75 \mathrm{E} & 90 \mathrm{E} & 105 \mathrm{E} & 120 \mathrm{E} & 135 \mathrm{E} & 150 \mathrm{E}\end{array}$

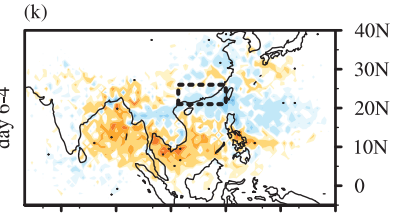

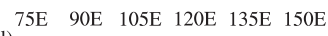
(1) $^{7}$

Diff

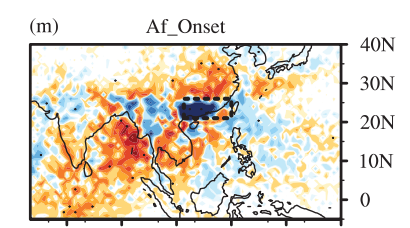

$\begin{array}{llllll}75 \mathrm{E} & 90 \mathrm{E} & 105 \mathrm{E} & 120 \mathrm{E} & 135 \mathrm{E} & 150 \mathrm{E}\end{array}$ (n)

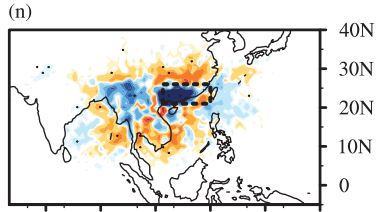

$75 \mathrm{E} \quad 90 \mathrm{E} \quad 105 \mathrm{E} \quad 120 \mathrm{E} \quad 135 \mathrm{E} \quad 150 \mathrm{E}$ (o)

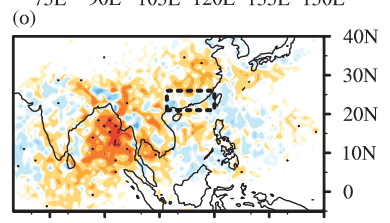

$75 \mathrm{E} \quad 90 \mathrm{E} \quad 105 \mathrm{E} \quad 120 \mathrm{E} \quad 135 \mathrm{E} \quad 150 \mathrm{E}$ (p) ${ }^{75}$

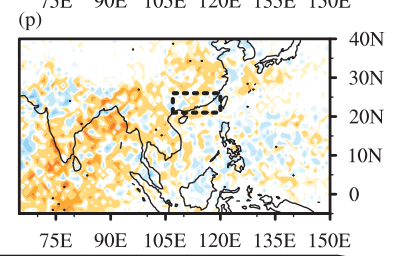

\begin{tabular}{cccccccc|cc|cccccc}
-2 & -1.5 & -1 & -0.5 & -0.3 & -0.1 & -0.05 & 0 & 0.05 & 0.1 & 0.3 & 0.5 & 1 & 1.5 & 2
\end{tabular}

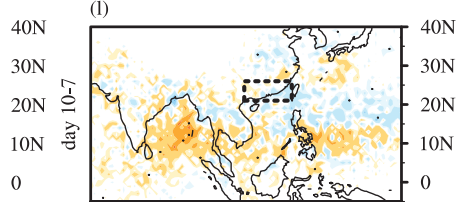

$75 \mathrm{E} \quad 90 \mathrm{E} \quad 105 \mathrm{E} \quad 120 \mathrm{E} \quad 135 \mathrm{E} \quad 150 \mathrm{E}$

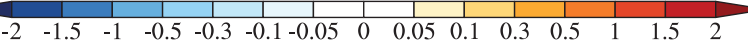

FIG. 6. As in Fig. 5, but for the spatial patterns of evaporation minus precipitation derived from all the target back-tracking trajectories. Units: $\mathrm{kg} \mathrm{m}^{-2}$.

4-6, followed by days 7-10 (Figs. $5 \mathrm{~m}-\mathrm{p}$ ). The decrement over regions to the east of South China is contributed by both days 6-7 and 1-3.

The spatial patterns of changes in evaporation minus precipitation (i.e., the changes in specific humidity) are shown in Fig. 6. For the FRS precipitation over South China before the onset of SCSSM, moisture source regions (evaporation minus precipitation greater than 0 ) occur over the Indian Ocean, the northwestern Pacific, the South China Sea, North China, and most regions of the Indian subcontinent, while moisture sink regions (evaporation minus precipitation less than 0 ) occur over South China, Southeast Asia, and the western portion of the Indian subcontinent (Fig. 6a). The distributions of moisture sink and source regions for the phase after the onset of SCSSM are similar to that for the phase before the onset of SCSSM (Fig. 6e).

For both the phases before and after the onset of SCSSM, North China, the northwestern Pacific, and the South China Sea can contribute moisture to the target precipitation throughout the entire back-tracking period but with different magnitudes over different back-tracking periods. The Indian Ocean tends to be the moisture source region over days 4-6 and 7-10 for the phase before the onset of SCSSM but over the entire back-tracking period for the phase after the onset of SCSSM. Southeast Asia tends to act as a moisture-sink region over all back-tracking days during the whole FRS, suggesting that the target air particles would release a large amount of moisture over this region before reaching South China.

Compared to the results obtained during dry years for both the phases before the onset of SCSSM, the Bay of Bengal, Southeast Asia, and the South China Sea contributed more moisture to the precipitation occurring over South China during wet years. More moisture would be released over South China under these conditions, implying that more precipitation would occur over South China during wet years. For Southeast Asia and the South China Sea, a greater moisture contribution to the target region mainly occurs over days $1-3$, followed by days $4-6$ and 7-10. For the Bay of Bengal, a greater moisture contribution to South China mainly occurs over days $4-6$, followed by days 7-10. The release of moisture over South China and the regions to the east mainly occurs over days $1-3$. Compared to the results before the onset of SCSSM, the increment of moisture over South China Sea (the Bay of Bengal) would be larger (smaller) after the onset of SCSSM.

The moisture from ocean regions tends to contribute a lot to the precipitation over South China before and after the onset of SCSSM, especially with a larger magnitude for the latter over the Indian Ocean. However, because of the long distance in reaching South China, the moisture originating from ocean sources tends to be largely reduced over Southeast Asia because of the undergoing releasing processes before precipitating over the target region. 
(a)

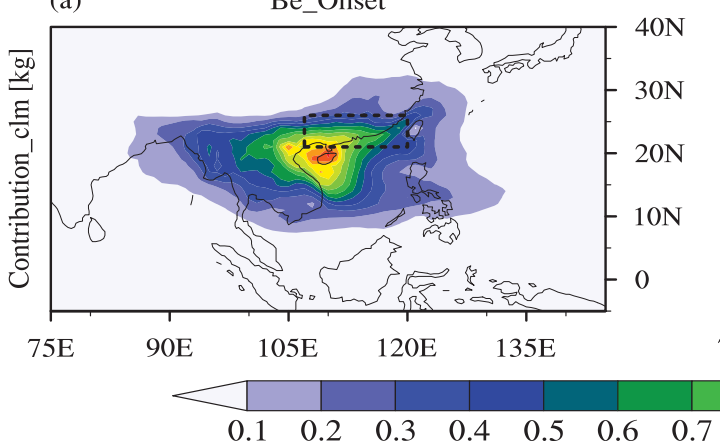

(c)

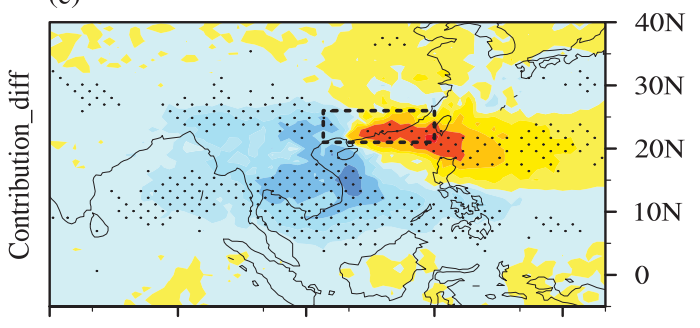

$75 \mathrm{E}$ (b)

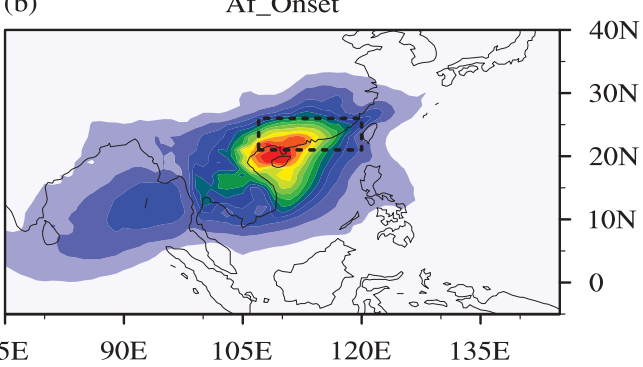

$40 \mathrm{~N}$

(d)

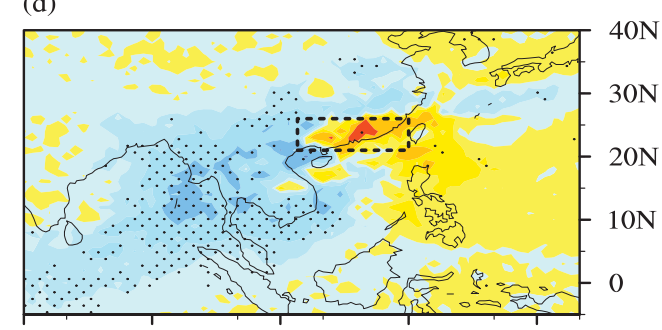

$\begin{array}{lllll}75 \mathrm{E} & 90 \mathrm{E} & 105 \mathrm{E} & 120 \mathrm{E} & 135 \mathrm{E}\end{array}$
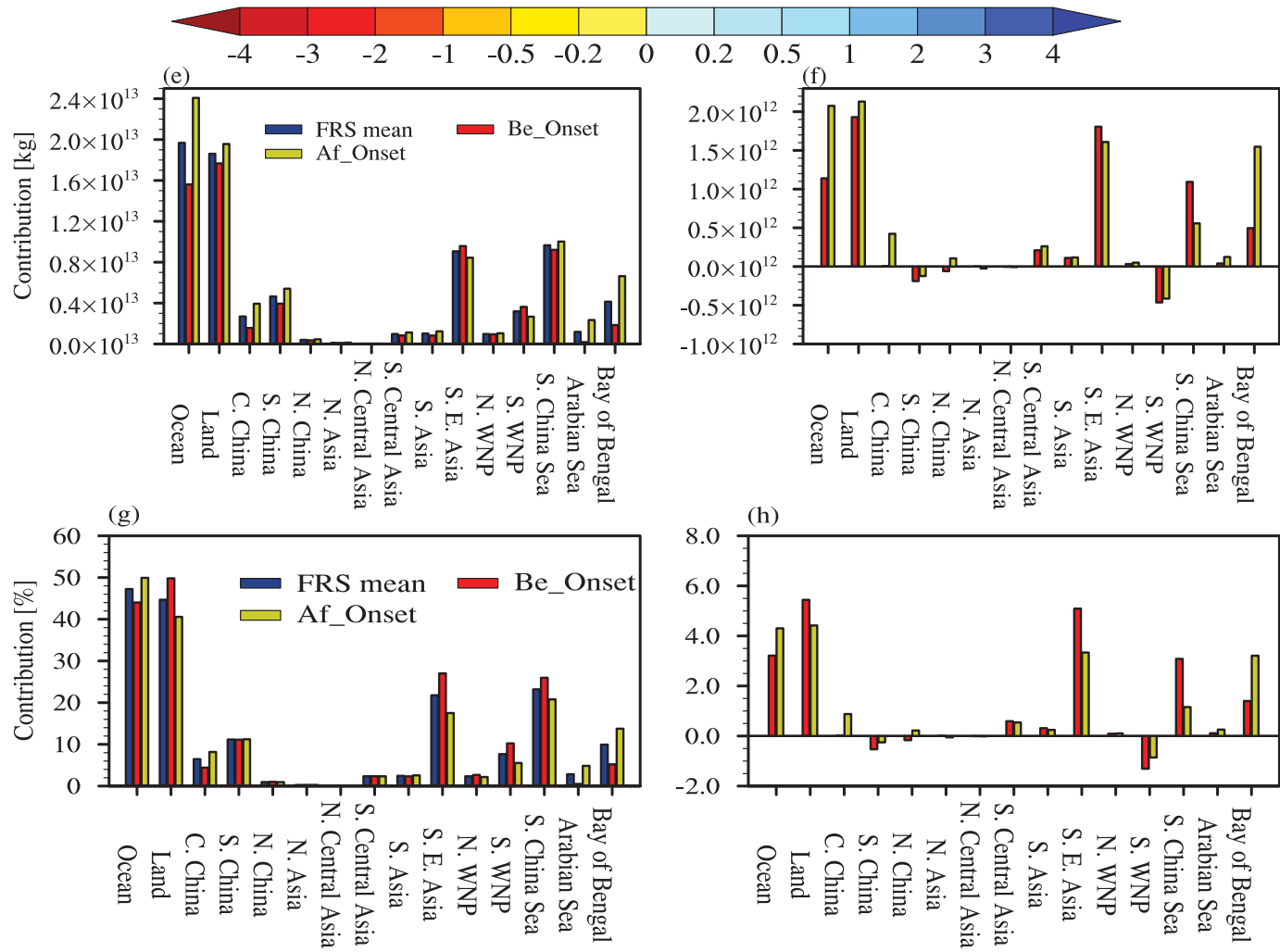

FIG. 7. Spatial patterns and area-averaged results for the moisture contribution to FRS precipitation in South China over the back-tracking 10 days. (a),(b) Spatial patterns for the long-term mean before and after the onset of SCSSM, respectively (units: $10^{10} \mathrm{~kg}$ ). (c),(d) Composite differences between wet and dry years before and after the onset of SCSSM, respectively (units: $10^{9} \mathrm{~kg}$ ). (e),(f) Area-averaged moisture contribution for the climate mean and the composite differences between wet and dry years, respectively (units: kg). (g),(h) Area-averaged moisture contribution percentage for the climate mean and the composite differences between wet and dry years, respectively (units: \%). 
TABLE 3. The moisture contribution of the major source regions (see Fig. 1) to the climatological FRS precipitation over South China. Units: \%.

\begin{tabular}{lccc}
\hline \hline & \multicolumn{3}{c}{ Time } \\
\cline { 2 - 4 } Source region & FRS mean & Be_Onset & Af_Onset \\
\hline Ocean & 47.25 & 44.01 & 49.93 \\
Land & 44.68 & 49.81 & 40.57 \\
C. China & 6.46 & 4.42 & 8.17 \\
S. China & 11.16 & 11.12 & 11.21 \\
N. China & 0.96 & 1.01 & 0.94 \\
N. Asia & 0.26 & 0.27 & 0.27 \\
N. Central Asia & 0.07 & 0.08 & 0.06 \\
S. Central Asia & 2.34 & 2.36 & 2.34 \\
S. Asia & 2.45 & 2.32 & 2.56 \\
S. E. Asia & 21.77 & 27.01 & 17.51 \\
N. WNP & 2.34 & 2.67 & 2.17 \\
S. WNP & 7.66 & 10.23 & 5.54 \\
S. China Sea & 23.19 & 25.96 & 20.78 \\
Arabian Sea & 2.84 & 0.50 & 4.85 \\
Bay of Bengal & 9.93 & 5.21 & 13.76 \\
\hline
\end{tabular}

\section{c. Moisture source contributions and the influence of sea surface temperature changes}

By considering the interval moisture uptake/releasing processes, the moisture contributions associated with the FRS precipitation over South China are quantified in this section.

To address the moisture sources in detail, the spatial patterns of moisture contribution are first discussed (Figs. 7a-d). At the long-term mean time scale for both the phases before and after the onset of SCSSM, the moisture contributions form a large band extending from South China to the northern part of the South China Sea, with the largest center located at the southwestern corner of South China to the northwestern part of the South China Sea (Figs. 7a,b). In addition, the moisture from the eastern part of Southeast Asia and the western part of the northwestern Pacific Ocean also contribute greatly to precipitation in South China before and after the onset of SCSSM. The moisture from regions to the southwest of South China can arrive at the target region by passing the high mountains over Southeast Asia. Note that the moisture from the Indian Ocean contributes much more to the FRS precipitation after than before the onset of SCSSM. The other regions also contribute to the FRS precipitation in South China but with a much lower magnitude.

Compared to the results obtained during dry years for the phase before the onset of SCSSM, the moisture contributions increase significantly over Southeast Asia, the western part of the South China Sea, and the northeastern part of the Bay of Bengal but decrease significantly over the eastern part of South China and western part of the northwestern Pacific Ocean during wet years (Fig. 7c). As for the phase after the onset of SCSSM, the moisture contributions increase significantly over the northern and southern parts of Southeast Asia, the Bay of Bengal, and the middle-western part of the South China Sea, but decrease slightly over the eastern part
TABLE 4. Moisture contribution differences (with respect to the climatological results) of the major source regions between wet and dry years to the FRS precipitation over South China. Units: \%.

\begin{tabular}{lcc}
\hline \hline & \multicolumn{2}{c}{ Time } \\
\cline { 2 - 3 } Subregion & Be_Onset & Af_Onset \\
\hline Ocean & 3.21 & 4.30 \\
Land & 5.44 & 4.42 \\
C. China & 0.02 & 0.88 \\
S. China & -0.53 & -0.25 \\
N. China & -0.17 & 0.22 \\
N. Asia & 0.01 & -0.05 \\
N. Central Asia & -0.01 & -0.01 \\
S. Central Asia & 0.59 & 0.54 \\
S. Asia & 0.31 & 0.24 \\
S. E. Asia & 5.09 & 3.34 \\
N. WNP & 0.09 & 0.10 \\
S. WNP & -1.31 & -0.86 \\
S. China Sea & 3.08 & 1.16 \\
Arabian Sea & 0.11 & 0.26 \\
Bay of Bengal & 1.40 & 3.21 \\
\hline
\end{tabular}

of South China and western part of the northwestern Pacific Ocean during wet years (Fig. 7d).

To identify the key moisture source regions as well as their relative importance to the precipitation over South China, the moisture contributions of 13 subregions are quantified. These subregions are South China, Central China, North China, North Asia, North Central Asia, South Central Asia, South Asia, Southeast Asia, the northern part of the northwestern Pacific, the southern part of the northwestern Pacific, the South China Sea, the Arabian Sea, and the Bay of Bengal (Fig. 1a). Before the onset of SCSSM, land sources contribute more moisture to the climatological FRS precipitation over South China than the ocean sources (Table 3). In terms of the subregions, the largest contributor to the climatological precipitation over South China is Southeast Asia (27.01\%), followed by the South China Sea $(25.96 \%)$, South China $(11.12 \%)$, and the southern part of the northwestern Pacific Ocean $(10.23 \%)$. After the onset of SCSSM, however, the moisture associated with climatological FRS precipitation is mainly contributed by ocean regions, followed by land regions. The main source regions for the climatological precipitation over South China are the South China Sea $(20.78 \%)$, Southeast Asia (17.51\%), the Bay of Bengal $(13.76 \%)$, and South China $(11.21 \%)$. The moisture from other source regions also contributes to FRS precipitation over South China but at a lower ratio.

Compared to the results obtained during dry years for both the phase before and the phase after the onset of SCSSM, the moisture contributions over both ocean and land regions increase during wet years, but with a larger magnitude for the latter (Figs. 7f,h and Table 4). Note that the larger magnitude of moisture contribution over ocean than land regions is more obviously seen before the onset of SCSSM. Before the onset of SCSSM, the increased moisture contribution mainly comes 
(a)

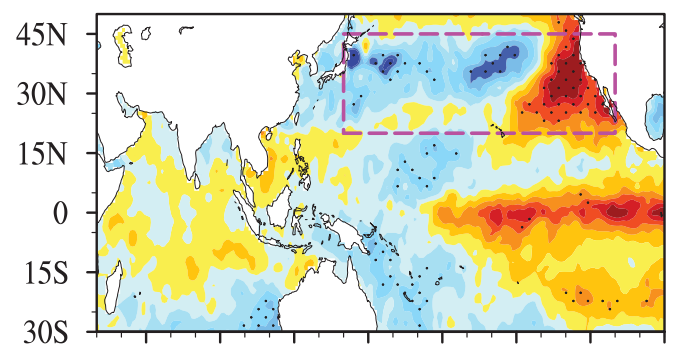

$60 \mathrm{E} \quad 90 \mathrm{E} 120 \mathrm{E} 150 \mathrm{E} \quad 180$ 150W120W 90W (b)

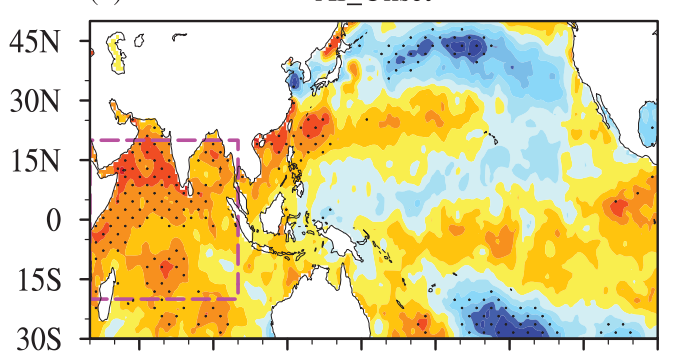

60E 90E 120E 150E 180 150W120W 90W

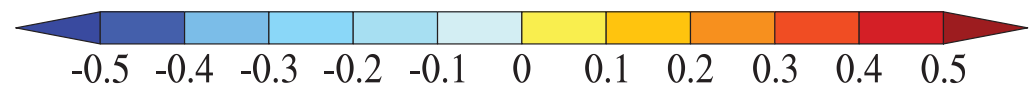

(c)

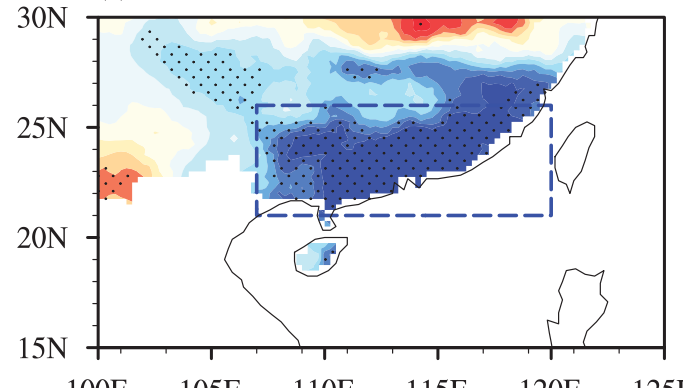

(d)

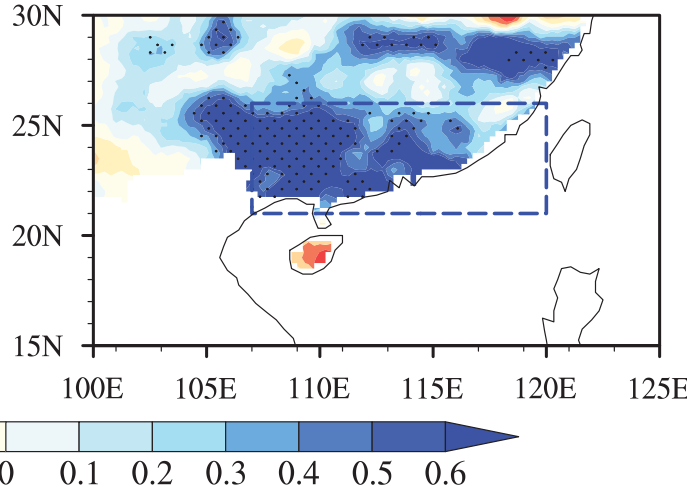

(e)

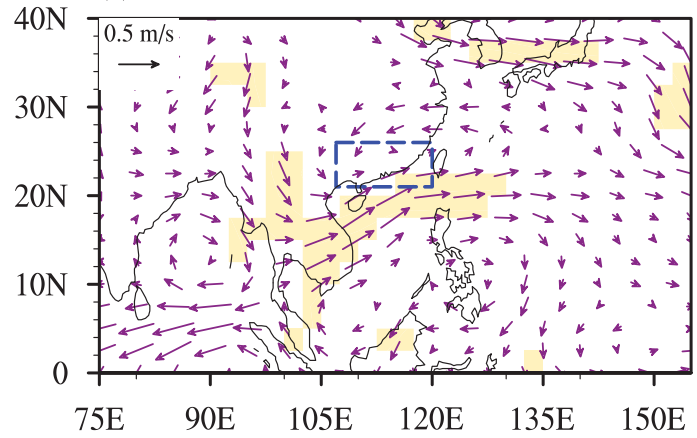

(f)

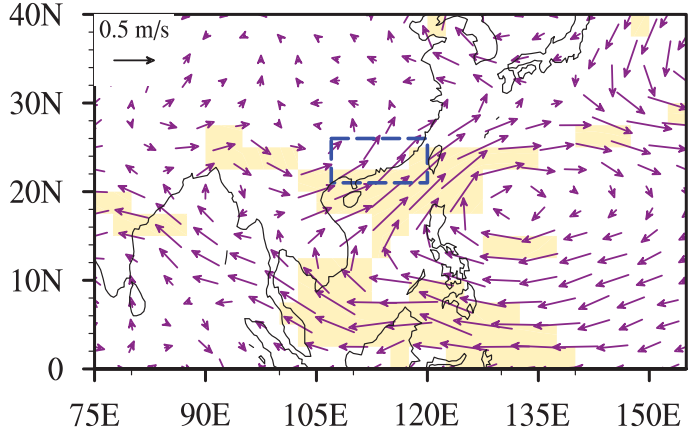

FIG. 8. Spatial distributions of the sea surface temperature anomalies and atmospheric circulation anomalies in association with the changes in FRS precipitation. (a),(b) Composite differences in sea surface temperature anomalies between wet and dry years. Units: K. (c),(d) Precipitation regressed onto the normalized 5-yr high-pass filtered $I_{\text {NNPEWC }}$ and $I_{\text {IOBM }}$, respectively. Units: $\mathrm{mm} \mathrm{day}^{-1}$. (e),(f) As in (c) and (d), but for the horizontal winds at $850 \mathrm{hPa}$. Units: $\mathrm{m} \mathrm{s}^{-1}$. Columns indicate the results (left) before and (right) after the onset of SCSSM. The magenta dashed boxes in (a) and (b) indicate the regions northern part of North Pacific and Indian Oceans, respectively.

from Southeast Asia (with a percentage rate of approximately $47.56 \%)$, followed by the South China Sea $(28.79 \%)$ and the Bay of Bengal (13\%). After the onset of SCSSM, the increased moisture mainly comes from Southeast Asia (33.53\%), followed by the Bay of Bengal (32.26\%), the South China Sea (11.63\%), and the central part of China $(8.82 \%)$.

For both the phases before and after the onset of SCSSM, the moisture contribution over the southern part of the western
North Pacific decreases during wet years. In total, land regions $(66.87 \%)$ contribute much more than ocean regions $(37.13 \%)$ to the interannual variation in moisture before the onset of SCSSM. As to the phase after the onset of SCSSM, the contribution of land regions $(50.66 \%)$ is a bit larger than that of ocean regions (49.34\%). Therefore, interannual variations in the moisture contribution for both the phase before and after the onset of SCSSM are mainly dominated by land regions, followed by ocean 
regions, and the role of land regions is more important before the onset of SCSSM (with respect to the results after the onset of SCSSM).

The changes in FRS precipitation over South China are impacted by the variations in sea surface temperature. Before the onset of SCSSM, the significant changes in sea surface temperature associated with the precipitation difference between wet and dry years mainly occur over the northern part of the North Pacific, showing a west cold-east warm pattern (Fig. 8a). After the onset of SCSSM, the corresponding sea surface temperature anomalies show a uniform warming over nearly the whole Indian Ocean (Fig. 8b). Therefore, we define an index to reflect the east-west contrast of sea sure temperature anomalies over the northern part of North Pacific $\left(I_{\text {NNPEWC }}\right)$ for the precipitation before the onset of SCSSM:

$$
I_{\mathrm{NNPEWC}}=\mathrm{SSTA}_{E}-\mathrm{SSTA}_{W},
$$

where $\mathrm{SSTA}_{E}$ and $\mathrm{SSTA}_{W}$ indicate the regional averaged sea surface temperature anomaly over the regions $20^{\circ}-45^{\circ} \mathrm{N}$, $210^{\circ}-250^{\circ} \mathrm{E}$ and $20^{\circ}-45^{\circ} \mathrm{N}, 140^{\circ}-210^{\circ} \mathrm{E}$, respectively. For the precipitation after the onset of SCSSM, the Indian Ocean basin mode index $\left[I_{\text {IOBM }}\right.$, the regional averaged sea surface temperature anomaly over tropical Indian Ocean $\left(20^{\circ} \mathrm{S}-20^{\circ} \mathrm{N}\right.$, $40^{\circ}-100^{\circ} \mathrm{E}$ )] is employed (Meyers 1996; Hu et al. 2019).

The 5-yr high-pass filtered $I_{\text {NNPEWC }}$ and $I_{\text {IOBM }}$ are significantly correlated with the regional averaged precipitation over South China before and after the onset of SCSSM, with values of 0.60 and 0.50 during 1979-2017 respectively. For the selected dry and wet years, the correlation coefficient between 5-yr high-pass filtered $I_{\text {NNPEWC }}\left(I_{\text {IOBM }}\right)$ and the regional averaged precipitation over South China before (after) the onset of SCSSM is larger, with a value of $0.63(0.65)$, passing the $5 \%$ significance level.

To address the spatial distributions, the precipitation over South China before and after the onset of SCSSM is then regressed ono the normalized $I_{\text {NNPEWC }}$ and $I_{\text {IOBM }}$, respectively (Figs. 8c,d). Note both the precipitation and sea surface temperature indices are applied by the 5-yr high-pass filter. Both the precipitation variations during the two phases show positive correlations with the corresponding normalized sea surface temperature indices over nearly the whole region of South China (Figs. 8c,d).

The atmospheric circulations before and after the onset of SCSSM are further regressed onto the corresponding normalized indices (Figs. 8e,f). In association with the west cold-east warm pattern of the sea surface temperature anomaly over the northern part of North Pacific before the onset of SCSSM, South China is dominated by the southwesterlies associated with the local anomalous cyclone and the anomalous anticyclone in the Philippines and South China Sea, transporting more moisture from the South China Sea and Southeast Asia into South China (Fig. 8e). Associated with the uniform warming over the Indian Ocean after the onset of SCSSM, South China is dominated by the southerlies/southwesterlies associated with the anomalous anticyclone over the northwestern Pacific, favoring more moisture from the South China Sea and Southeast Asia to the precipitation over South China
(Fig. 8f). Note that the relationship between Indian Ocean warming and the anomalous anticyclone over northwestern Pacific is seen in Wu et al. (2009). Favoring by the anomalous southerlies, the anomalous atmospheric circulations associated with the anomalous anticyclone expanding from the northeastern part of the Bay of Bengal to the northwestern part of Southeast Asia can also provide more moisture from the Bay of Bengal for South China.

\section{Summary}

A key step in understanding the dynamic mechanisms responsible for precipitation changes is revealing the corresponding moisture origins. To detect the moisture sources associated with the interannual variations in FRS precipitation occurring in South China over the 1979-2017 period, the FLEXPART model is employed in this study by using a moisture source attribution method considering the interval moisture uptake/release processes. The main results are summarized as follows.

The results show that moisture contributions for the source regions of FRS precipitation over South China are impacted by the SCSSM activities. Before the onset of SCSSM, the moisture associated with climatological precipitation over South China is mainly contributed by the land regions, followed by the ocean regions. In terms of the subregions, the main contributors are Southeast Asia (27.01\%), the South China Sea $(25.96 \%)$, local regions $(11.12 \%)$, and the southern part of the northwestern Pacific (10.23\%). However, after the onset of SCSSM, ocean regions contribute more moisture to the climatological precipitation than the land regions, and the largest contributor is the South China Sea (20.78\%), followed by Southeast Asia (17.51\%), the Bay of Bengal (13.76\%), and its local regions $(11.21 \%)$. The moisture originating from other source regions also contributes to the FRS precipitation over South China for both the phases before and after the onset of SCSSM but with a much smaller ratio.

There is an obvious difference in the moisture contribution to FRS precipitation over South China between dry and wet years. Compared to the results obtained during dry years, the moisture contribution over both ocean and land regions increases during wet years with a much larger magnitude for the latter during the phase before the onset of SCSSM, but with comparable magnitude during the phase after the onset of SCSSM. Consequently, land and ocean regions contribute $66.87 \%$ and $33.13 \%$ in the interannual variations of FRS precipitation over South China before the onset of SCSSM, respectively. The increase in moisture contribution mainly comes from Southeast Asia (47.56\%), followed by the South China Sea $(28.79 \%)$ and the Bay of Bengal (13\%). As to the interannual variations of precipitation after the onset of SCSSM, the contributions of land and ocean sources are $50.66 \%$ and $49.34 \%$, respectively. In terms of subregions, the main contributors are Southeast Asia (33.53\%), the Bay of Bengal (32.26\%), and the South China Sea $(11.63 \%)$.

The interannual variations of FRS precipitation over South China are significantly correlated with the changes in sea 
surface temperature over the northern part of North Pacific and tropical Indian Ocean for the phase before and after the onset of SCSSM, respectively. In association with the positive east-west contrast of sea surface temperature anomalies over the northern part of North Pacific during the phase before the onset of SCSSM, the anomalous southwesterlies over South China can transport more moisture from the South China Sea and Southeast Asia into the target region because of the local anomalous cyclone and the anomalous anticyclone over the Philippines and the South China Sea. Accompanied by the uniform warming over tropical Indian Ocean after the onset of SCSSM, the anomalous anticyclone occurs over both the northwestern Pacific and the northwestern part of Southeast Asia. As a result, South China is dominated by the southeasterlies, which contribute moisture from Southeast Asia, the South China Sea, and the Bay of Bengal to the precipitation over South China.

Based on the backward-tracked air particles at several vertical levels of the atmosphere over the target region, Chen and Luo (2018) suggest that ocean regions contribute much more moisture to the climatological FRS precipitation over South China than land regions for both the phases before and after the onset of SCSSM. As revealed in this study, the target air particles would release a large amount of moisture in the way reaching South China from source regions (especially ocean sources). By analyzing the backward-tracked air particles of the whole atmosphere over the target region, the estimated moisture contribution of ocean regions in this study is smaller (larger) than that of land regions before (after) the onset of SCSSM, which is different from the results in Chen and Luo (2018).

This study reveals that land sources play an important role in the precipitation changes over South China, especially for the interannual variations before the onset of SCSSM. This is partly because target air particles reaching South China from land regions with a shorter distance from South China would release less moisture than those from ocean regions far away. In addition, with regard to the employed moisture detection method, the moisture released by the earlier precipitation event over the land regions is also regarded as part of the land sources (Sodemann et al. 2008; Peng et al. 2020). The water cycle of climate system is complex across multiple time scales and spatial scales. The moisture source studies associated with the precipitation event mainly focus on synoptic time scales (i.e., the precipitation event is tracked backward for 10 days). The moisture from land sources (such as Southeast Asia) contributing to precipitation over South China would be further traced backward, which may be largely contributed by the ocean regions. Thus, at a longer time scale, ocean sources should eventually contribute much more moisture to the precipitation over South China than the land sources.

Acknowledgments. This work was jointly supported by the National Key R\&D Program of China (Grant 2018YFC1505801), the National Natural Science Foundation of China (Grant 41905070), and the Guangdong Basic and Applied Basic Research Foundation (2020A1515010485, 2021A1515011421).

\section{REFERENCES}

Arthur, D., and S. Vassilvitskii, 2007: SODA'07: Proc. 18th Annual ACM-SIAM Symp. on Discrete Algorithms. New Orleans, LA, Society for Industrial and Applied Mathematics, 1027-1035.

Bohlinger, P., A. Sorteberg, and H. Sodemann, 2017: Synoptic conditions and moisture sources actuating extreme precipitation in Nepal. J. Geophys. Res. Atmos., 122, 122653-122671, https://doi.org/10.1002/2017JD027543.

Cai, X., Y. Wang, and J. Xu, 2002: Diagnostic analysis on impact of convective activity anomalies over tropic on flood/drought during the first rainy season in South China (in Chinese). $J$. Trop. Meteor., 18, 157-164.

Chang, Y., and Coauthors, 2006: Features of moisture transport of in pre-summer flood season of drought and flood years over South China (in Chinese). Plateau Meteor., 25, 1064-1070.

Chen, Y., and Y. Luo, 2018: Analysis of paths and sources of moisture for the south China rainfall during the presummer rainy season of 1979-2014. J. Meteor. Res., 32, 744-757, https://doi.org/10.1007/s13351-018-8069-7.

Chen, Y. M., and Y. F. Qian, 2005: Numerical study of influence of the SSTA in western Pacific warm pool on precipitation in the first flood period in south China (in Chinese). J. Trop. Meteor., 21, 13-23.

Chi, Y. Z., J. H. He, and Z. W. Wu, 2005: Features analysis of the different precipitation periods in the pre-flood season in South China (in Chinese). J. Nanjing Inst. Meteor., 28, 163-171.

CMA, 2017: Monitoring indicators of the South China Sea summer monsoon (in Chinese). Department of Forecasting and Networking, China Meteorological Administration, 8 pp.

Drumond, A., R. Nieto, and L. Gimeno, 2011: Sources of moisture for China and their variations during drier and wetter conditions in 2000-2004: A Lagrangian approach. Climate Res., 50, 215-225, https://doi.org/10.3354/cr01043.

Durán-Quesada, A. M., L. Gimeno, J. A. Amador, and R. Nieto, 2010: Moisture sources for Central America: Identification of moisture sources using a Lagrangian analysis technique. $J$. Geophys. Res., 115, D05103, https://doi.org/10.1029/ 2009JD012455.

Feng, L., and T. Zhou, 2012: Water vapor transport for summer precipitation over the Tibetan Plateau: Multidata set analysis. J. Geophys. Res., 117, D20114, https://doi.org/10.1029/ 2011JD017012.

Gao, H., and Coauthors, 2001: Definition of 40-year onset data of South China Sea summer monsoon (in Chinese). J. Nanjing Inst. Meteor., 03, 379-383.

Gimeno, L., A. Drumond, R. Nieto, R. M. Trigo, and A. Stohl, 2010: On the origin of continental precipitation. Geophys. Res. Lett., 37, L13804, https://doi.org/10.1029/2010GL043712.

$\mathrm{Gu}, \mathrm{W}$., and Coauthors, 2018: Interannual variations of the first rainy season precipitation over south China. J. Climate, 31, 623-640, https://doi.org/10.1175/JCLI-D-17-0284.1.

He, J., and Coauthors, 2001: Establishment date of South China Sea summer monsoon and monsoon index (in Chinese). China Meteorological Press, 1-4.

$\mathrm{Hu}$, S., and Coauthors, 2019: A comparison of full-field and anomaly initialization for seasonal prediction of Indian Ocean basin mode. Climate Dyn., 53, 6089-6104, https://doi.org/10. 1007/s00382-019-04916-9.

Huang, L., Y. Luo, and D. L. Zhang, 2018: The relationship between anomalous presummer extreme rainfall over south 
China and synoptic disturbances. J. Geophys. Res. Atmos., 123, 3395-3413, https://doi.org/10.1002/2017JD028106.

Huang, W., and Coauthors, 2018: Moisture sources for wintertime extreme precipitation events over South China during 1979-2013. J. Geophys. Res. Atmos., 123, 6690-6712, https:// doi.org/10.1029/2018JD028485.

Huang, Y., and X. Cui, 2015: Moisture sources of torrential rainfall events in the Sichuan Basin of China during summers of 2009-13. J. Hydrometeor., 16, 1906-1917, https://doi.org/10. 1175/JHM-D-14-0220.1.

Jiang, Z., and Coauthors, 2017: Impact of moisture source variation on decadal-scale changes of precipitation in North China from 1951 to 2010. J. Geophys. Res. Atmos., 122, 600-613, https://doi.org/10.1002/2016JD025795.

Kalnay, E., and Coauthors, 1996: The NCEP/NCAR 40-Year Reanalysis Project. Bull. Amer. Meteor. Soc., 77, 437-472, https://doi. org/10.1175/1520-0477(1996)077<0437:TNYRP > 2.0.CO;2.

Läderach, A., and H. Sodemann, 2016: A revised picture of the atmospheric moisture residence time. Geophys. Res. Lett., 43, 924-933, https://doi.org/10.1002/2015GL067449.

Li, H., and Coauthors, 2020: Multiscale analysis of a record-breaking heavy rainfall event in Guangdong, China. Atmos. Res., 232, 104703, https://doi.org/10.1016/j.atmosres.2019.104703.

Li, X., W. Zhou, and Y. D. Chen, 2016: Detecting the origins of moisture over southeast China: Seasonal variation and heavy rainfall. Adv. Atmos. Sci., 33, 319-329, https://doi.org/10.1007/ s00376-015-4197-5.

Liang, J., and S. Wu, 2001: Formation reasons of drought and flood in the rain season of Guangdong and preceding impact factors (in Chinese). J. Trop. Meteor., 17, 97-108.

Meyers, G., 1996: Variation of Indonesian throughflow and the El Niño-Southern Oscillation. J. Geophys. Res., 101, 122255122263, https://doi.org/10.1029/95JC03729.

Nieto, R., L. Gimeno, and R. M. Trigo, 2006: A Lagrangian identification of major sources of Sahel moisture. Geophys. Res. Lett., 33, L18707, https://doi.org/10.1029/2006GL027232.

Numaguti, A., 1999: Origin and recycling processes of precipitating water over the Eurasian continent: Experiments using an atmospheric general circulation model. J. Geophys. Res., 104, 1957-1972, https://doi.org/10.1029/1998JD200026.

Pathak, A., S. Ghosh, and P. Kumar, 2014: Precipitation recycling in the Indian subcontinent during summer monsoon. $J$. Hydrometeor., 15, 2050-2066, https://doi.org/10.1175/JHM-D13-0172.1.

— , and Coauthors, 2017: Role of oceanic and land moisture sources and transport in the seasonal and interannual variability of summer monsoon in India. J. Climate, 30, 18391859, https://doi.org/10.1175/JCLI-D-16-0156.1.

Peng, D., and T. Zhou, 2017: Why was the arid and semiarid northwest China getting wetter in the recent decades? J. Geophys. Res. Atmos., 122, 9060-9075, https://doi.org/10.1002/ 2016JD026424.

,-- , L. Zhang, and B. Wu, 2018: Human contribution to the increasing summer precipitation in Central Asia from 1961 to 2013. J. Climate, 31, 8005-8021, https://doi.org/10. 1175/JCLI-D-17-0843.1.

,-- , and - 2020: Moisture sources associated with precipitation during dry and wet seasons over Central Asia. $J$. Climate, 33, 102755-102771, https://doi.org/10.1175/JCLI-D20-0029.1.

Qiang, X. M., and X. Q. Yang, 2013: Relationship between the first rainy season precipitation anomaly in South China and the sea surface temperature anomaly in the Pacific (in
Chinese). Chin. J. Geophys., 56, 2583-2593, https://doi.org/10. 6038/cjg20130808.

Rayner, N., and Coauthors, 2003: Global analyses of sea surface temperature, sea ice, and night marine air temperature since the late nineteenth century. J. Geophys. Res., 108, 4407, https://doi.org/10.1029/2002JD002670.

Saha, S., and Coauthors, 2010: The NCEP Climate Forecast System Reanalysis. Bull. Amer. Meteor. Soc., 91, 1015-1058, https://doi.org/10.1175/2010BAMS3001.1.

— version 2. J. Climate, 27, 2185-2208, https://doi.org/10.1175/ JCLI-D-12-00823.1.

Salih, A. A. M., and Coauthors, 2016: Sources of Sahelian-Sudan moisture: Insights from a moisture-tracing atmospheric model. J. Geophys. Res. Atmos., 121, 7819-7832, https://doi. org/10.1002/2015JD024575.

Seager, R., N. Naik, and G. A. Vecchi, 2010: Thermodynamic and dynamic mechanisms for large-scale changes in the hydrological cycle in response to global warming. J. Climate, 23, 46514668, https://doi.org/10.1175/2010JCLI3655.1.

Shi, Y., and Coauthors, 2020: A Lagrangian analysis of water vapor sources and pathways for precipitation in East China in different stages of the East Asian summer monsoon. J. Climate, 33, 977-992, https://doi.org/10.1175/JCLI-D-19-0089.1.

Sodemann, H., C. Schwierz, and H. Wernli, 2008: Interannual variability of Greenland winter precipitation sources: Lagrangian moisture diagnostic and North Atlantic Oscillation influence. J. Geophys. Res., 113, D03107, https://doi.org/10.1029/ 2007JD008503.

Stohl, A., and P. A. James, 2004: Lagrangian analysis of the atmospheric branch of the global water cycle. Part I: Method description, validation, and demonstration for the August 2002 flooding in central Europe. J. Hydrometeor., 5, 656-678, https://doi.org/10.1175/1525-7541(2004)005<0656:ALAOTA $>$ 2.0.CO;2.

- , and —-, 2005: Lagrangian analysis of the atmospheric branch of the global water cycle. Part II: Moisture transports between Earth's ocean basins and river catchments. J. Hydrometeor., 6, 961-984, https://doi.org/10.1175/JHM470.1.

— model FLEXPART version 6.2. Atmos. Chem. Phys., 5, 2461-2474, https://doi.org/10.5194/acp-5-2461-2005.

Suh, S. W., and Coauthors, 2015: An efficient early warning system for typhoon storm surge based on time-varying advisories by coupled ADCIRC and SWAN. Ocean Dyn., 65, 617646, https://doi.org/10.1007/s10236-015-0820-3.

Sun, B., and H. Wang, 2014: Moisture sources of semiarid grassland in China using the Lagrangian particle model FLEXPART. J. Climate, 27, 2457-2474, https://doi.org/10.1175/ JCLI-D-13-00517.1.

$\longrightarrow$, and -2015 : Analysis of the major atmospheric moisture sources affecting three sub-regions of East China. Int. J. Climatol., 35, 2243-2257, https://doi.org/10.1002/joc.4145.

Trenberth, K. E., 1998: Atmospheric moisture residence times and cycling: Implications for rainfall rates and climate change. Climatic Change, 39, 667-694, https://doi.org/10.1023/ A:1005319109110.

Vázquez, M., and Coauthors, 2016: Moisture transport into the Arctic: Source-receptor relationships and the roles of atmospheric circulation and evaporation. J. Geophys. Res. Atmos., 121, 132493-132509, https://doi.org/10.1002/2016JD025400.

Wang, Y., and L. Zhou, 2005: Observed trends in extreme precipitation events in China during 1961-2001 and the associated 
changes in large-scale circulation. Geophys. Res. Lett., 32, L09707, https://doi.org/10.1029/2005GL022574.

Wu, B., T. Zhou, and T. Li, 2009: Seasonally evolving dominant interannual variability modes of East Asian climate. J. Climate, 22, 2992-3005, https://doi.org/10.1175/2008JCLI2710.1.

Wu, H., Y. Du, and P. Qin, 2011: Climate characteristics and variation of rainstorm in south China (in Chinese). Meteor. Mon., 37, 1262-1269.

Wu, J., and X. J. Gao, 2013: A gridded daily observation dataset over China region and comparison with the other datasets. Chin. J. Geophys., 56, 1102-1111, https://doi.org/10.6038/cjg20130406.

Yang, H., and S. Q. Sun, 2005: The characteristics of longitudinal movement of the subtropical high in the western Pacific in the pre-rainy season in South China. Adv. Atmos. Sci., 22, 392-400, https://doi.org/10.1007/BF02918752.

Yang, Z., and Coauthors, 2018: Interannual variation and regime shift of the evaporative moisture sources for wintertime precipitation over southern China. J. Geophys. Res. Atmos., 123, 132168-132185, https://doi.org/10.1029/2018JD029513.
Yao, S., Q. Huang, and C. Zhao, 2016: Variation characteristics of rainfall in the pre-flood season of South China and its correlation with sea surface temperature of Pacific. Atmosphere, 7, 5, https://doi.org/10.3390/atmos7010005.

Yoo, C., 2006: Long term analysis of wet and dry years in Seoul, Korea. J. Hydrol., 318, 24-36, https://doi.org/10.1016/j.jhydrol. 2005.06.002.

Yuan, C., and Coauthors, 2019: Influences of tropical Indian and Pacific oceans on the interannual variations of precipitation in the early and late rainy seasons in South China. J. Climate, 32, 3681-3694, https://doi.org/10.1175/JCLI-D18-0588.1.

Yuan, F., and Coauthors, 2010: Temporal variations of the frontal and monsoon storm rainfall during the first rainy season in South China. Atmos. Oceanic Sci. Lett., 3, 243-247, https:// doi.org/10.1080/16742834.2010.11446876.

Zhong, L., L. Hua, and D. Luo, 2018: Local and external moisture sources for the Arctic warming over the Barents-Kara Seas. J. Climate, 31, 1963-1982, https://doi.org/10.1175/JCLI-D-170203.1. 